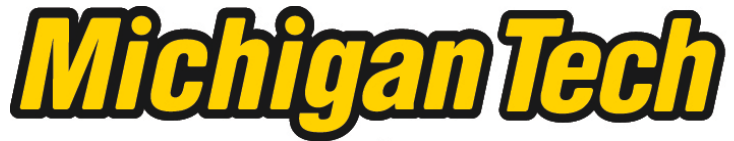 \\ Michigan Technological University Create the Future Digital Commons @ Michigan Tech
}

Dissertations, Master's Theses and Master's Reports - Open

Dissertations, Master's Theses and Master's

Reports

2012

\section{Habitat Associations of the Golden-Winged Warbler in Honduras}

Ruth E. Bennett

Michigan Technological University

Follow this and additional works at: https://digitalcommons.mtu.edu/etds

Part of the Forest Sciences Commons

Copyright 2012 Ruth E. Bennett

\section{Recommended Citation}

Bennett, Ruth E., "Habitat Associations of the Golden-Winged Warbler in Honduras", Master's Thesis, Michigan Technological University, 2012.

https://doi.org/10.37099/mtu.dc.etds/165

Follow this and additional works at: https://digitalcommons.mtu.edu/etds

8 Part of the Forest Sciences Commons 


\title{
HABITAT ASSOCIATIONS OF THE GOLDEN-WINGED WARBLER IN HONDURAS
}

\author{
By
}

Ruth E. Bennett

\begin{abstract}
A THESIS
Submitted in partial fulfillment of the requirements for the degree of MASTER OF SCIENCE

In Applied Ecology
\end{abstract}

MICHIGAN TECHNOLOGICAL UNIVERSITY

2012

(C) 2012 Ruth E. Bennett 
This thesis has been approved in partial fulfillment of the requirements for the Degree of MASTER OF SCIENCE in Applied Ecology.

School of Forest Resources and Environmental Science

Thesis Advisor: Joseph Bump

Committee Member: Blair Orr

Committee Member: $\quad$ David Flaspohler

Committee Member: Amber Roth

Committee Member: $\quad$ Ronald Gratz

School Dean: $\quad$ Terry Sharik 


\section{Table of Contents}

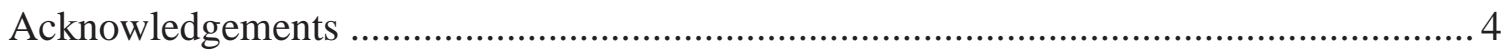

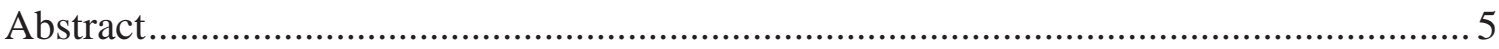

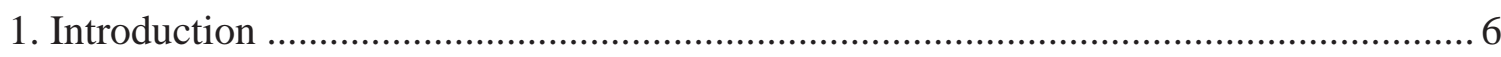

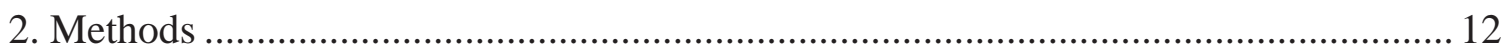

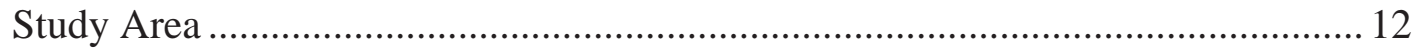

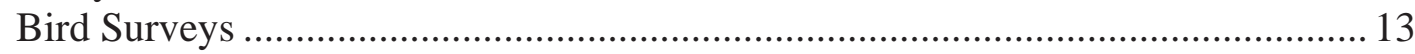

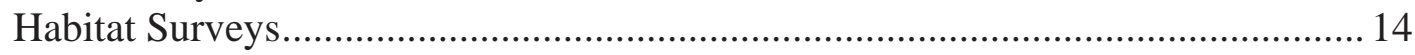

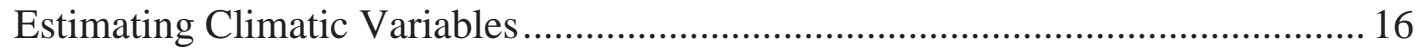

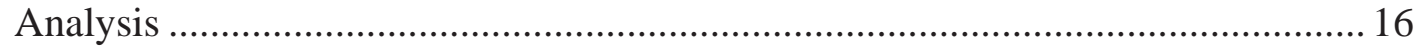

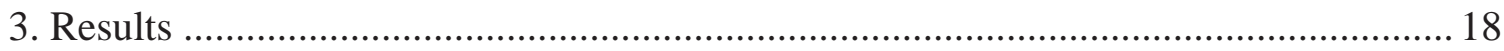

Spatial Segregation by Vermivora Species........................................................... 19

Spatial Segregation by Sex ……………………………................................. 19

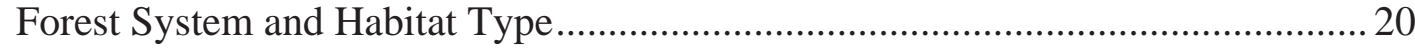

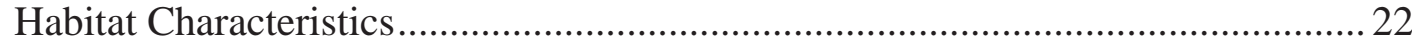

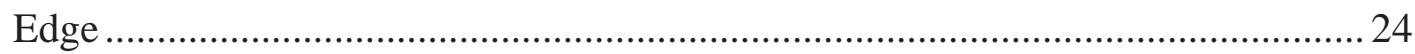

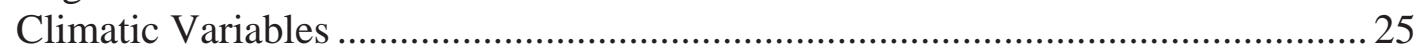

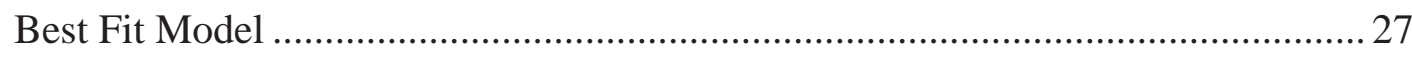

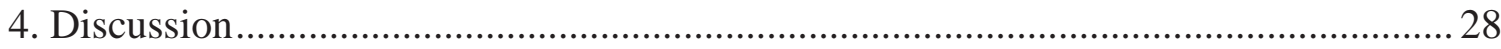

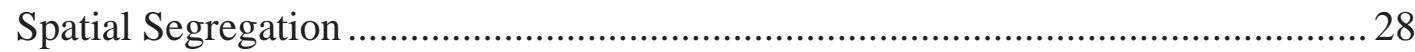

Forest System and Habitat Type...................................................................... 29

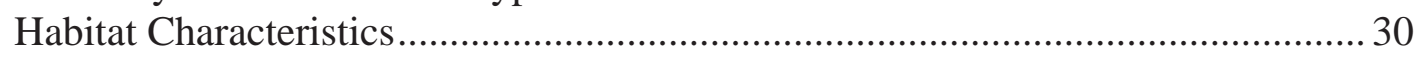

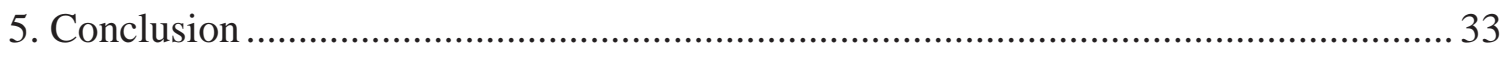

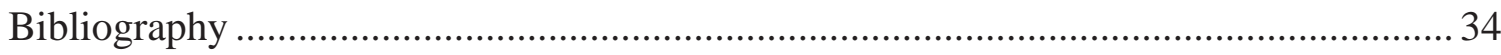

Appendix A: Description of Sites by Physical Characteristics ………………………..... 39

Appendix B: Percent composition data for plots with a Vermivora detection .................. 40

Appendix C: Summary statistics for plots with a Vermivora detection ............................. 41 


\section{Acknowledgements}

I would foremost like to thank my advisor Joseph Bump, who provided technical advice, logistical support, and funding to this research. He continuously encouraged me to develop and pursue my research interests and to collaborate with national and international partners. This thesis would not have been possible without the support and guidance of Amber Roth, who trained me in warbler capture methods, outlined the feasibility of a study in Honduras, and facilitated contact with the Golden-winged Warbler Working Group. Blair Orr, Director of the Master's International Peace Corps program at Michigan Tech, provided the training that allowed me to simultaneously conduct Peace Corps service and master's research. I am grateful to my committee members David Flaspohler and Ronald Gratz who provided input to improve the quality of this document.

I would like to thank the many organizations in Honduras and the United States that supported my research. The list of organizations includes the la Associación Hondureña de Ornithología, el Instituto de Conservación Forestal, la Universidad Nacional de Agricultura, el Programa de Educación Biologica, Escuela El Sembrador, Jardín Botanico Lancetilla, Parque Archeologico Los Naranjos, MAPANCE, the Lodge at PANACAM, Peace Corps Honduras, and the Ecosystem Science Center at Michigan Technological University. The Missouri Conservation Heritage Association also supported this research in collaboration with the Honduran Ornithological Association in the community of Vallecito, La Union, Olancho.

Many individuals also supported this research as guides, volunteers, and collaborators. The list includes Calixto Ordoñez, Mariela Ardon, Josue Matute, Jeff and Terry Daulton, Daniel Germer, Robert Gallardo, Malcolm Glasgow, Don Jose de San Luis Planes, Ronni de Vallecito, Don Luis de Celaque, Jessica Cañas, Jesse Kolar, Malcolm Stufkins, William Orellana, and Edwin Miranda. 


\section{Abstract}

The global population of the Neotropical migrant Golden-winged Warbler (Vermivora chrysoptera) has declined steadily over the past fifty years. While factors influencing this decline have been well researched on the breeding grounds, little is known about the distribution and habitat requirements of this warbler on its stationary non-breeding range. Recent efforts to quantify the non-breeding habitat requirements of this warbler have focused on Colombia and Costa Rica, though the species ranges as far north as the Yucatan Peninsula, Mexico. To address the gap in knowledge from the northern portion of the non-breeding range, I conducted 80 serial point-count surveys targeting Goldenwinged Warblers at eight field sites in Honduras, Central America. I found that Goldenwinged Warblers occupy a greater variety of habitats than previously recognized, including pine-oak forest and semi-deciduous broadleaf forest. I also documented habitat associations that have not been observed in other parts of the non-breeding range with respect to elevation, rainfall, and spatial segregation by sex. These results demonstrate the need to consider the entire non-breeding range in conservation planning, as Goldenwinged Warbler habitat associations appear to vary regionally. 


\section{Introduction}

The Golden-winged Warbler (Vermivora chrysoptera; hereafter GWWA), a NearcticNeotropical migratory songbird, has experienced one of the sharpest population declines of any songbird species in North America. According to the USGS Breeding Bird Survey, the population of the GWWA has decreased by $2.62 \%$ per year since the survey's inception in 1966 (Sauer et al. 2011). New analysis suggests that if this trend continues, the GWWA will lose 97\% of its global population by 2100 (Will et al. unpublished data). This startling decline prompted a petition to protect this species under the 1973 Endangered Species Act. The US Fish and Wildlife Service decided the petition was substantial after a 90-day review and issued a request to gather more data on the status of the species (76 FR 31920, 2011). The research presented in this thesis responds to that federal request by examining non-breeding habitat association for this species in Honduras.

Taxonomically, the GWWA belongs to the family Parulidae of the order Passeriformes. Males can be readily identified by their dark gray back and whitish underside with a black throat and mask, yellow crown, and yellow wing bar (Figure 1.1a). Females resemble the males but have lighter gray facial markings (Figure 1.1b). GWWAs hybridize with the closely related Blue-winged Warbler (Vermivora cyanoptera; hereafter BWWA; Figure1.1c) where the ranges overlap, and they produce a phenotypically distinct first generation hybrid called the Brewster's Warbler (hereafter BRWA; Figure 1.1d; Sibley 2003). 


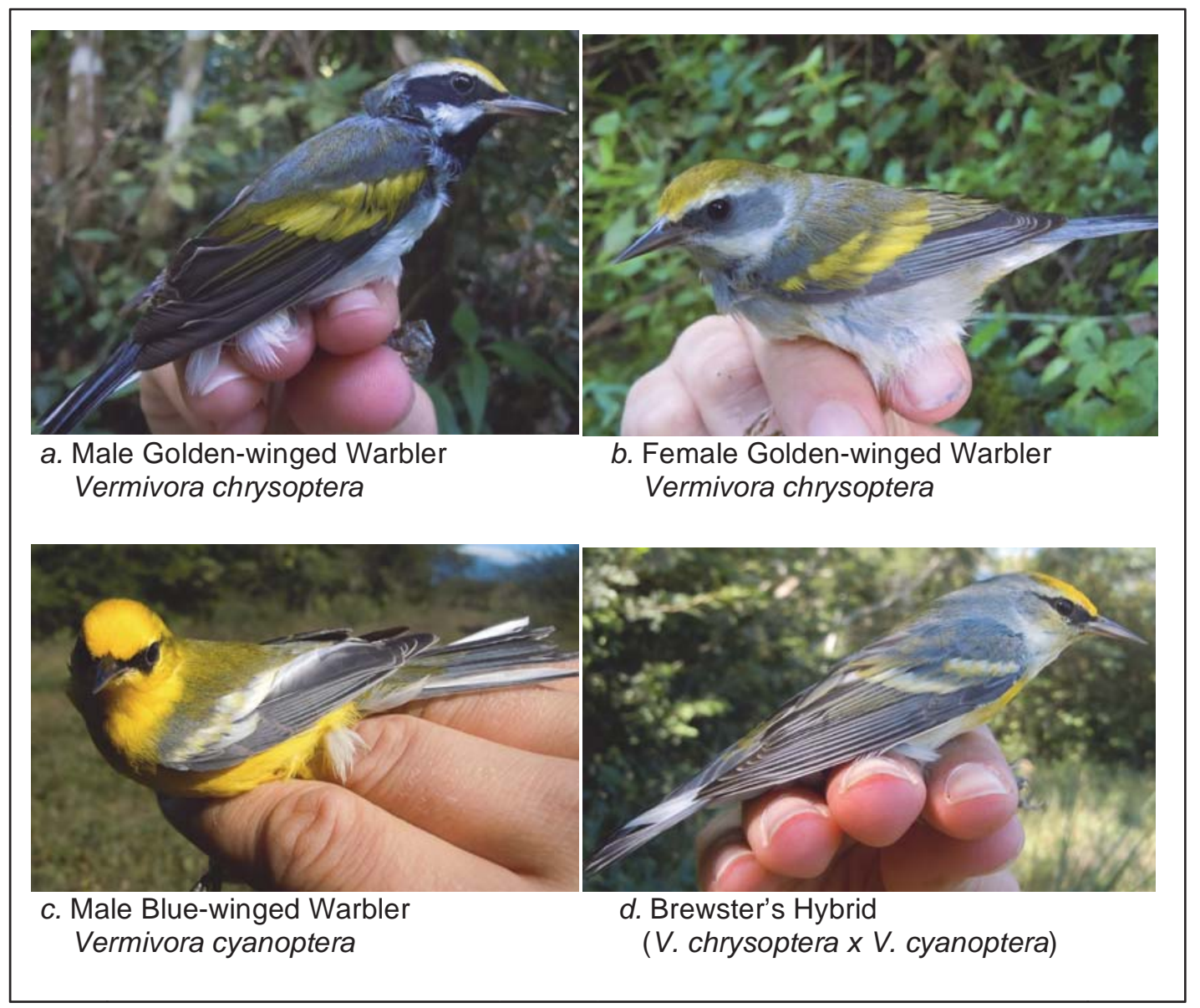

Figure 1.1: Physical appearance of Vermivora spp.

In their annual migratory cycle, GWWAs arrive in North America between April and May, breed between May and July, and migrate to Central and South America in August and September (eBird 2012). Their breeding range occurs as a narrow band around the Great Lakes from Southern Manitoba to Southern Quebec and along the Appalachian Mountains from extreme eastern Connecticut to northeastern Georgia (Roth et al. 2012). Within this breeding range, the population is declining most rapidly in the southeastern Appalachians and Northeastern states. Population change has averaged as high as $-9.8 \%$ per year in West Virginia (2000-2010) and extirpation appears to have occurred in the extreme southern portion of its breeding range and substantial parts of New England and the Midwest (Sauer et al. 2011, Gill 1980, Will et al. unpublished data). 
The habitat requirements, nesting success, and hybridization dynamics of GWWAs have been studied on the breeding range by ornithologists since the 1960s (Roth et al. 2012a). Research seeking to explain the population change has historically focused on the breeding grounds. Loss of early successional breeding habitat, competition and hybridization with the BWWA, and nest parasitism by the Brown-headed Cowbird (Molothrus ater) have been shown to be factors in the dramatic decline (Confer et al. 2003, Hunter et al. 2001, Buehler et al. 2007). While these events undoubtedly affect the population, they do not consider the full GWWA life cycle and therefore may not fully account for all factors responsible for the population decline.

In contrast to the breadth of research and publications available about the GWWA on its breeding range, little is known about the distribution and habitat requirements of the species in its non-breeding range, which stretches from southern Mexico to the northern Andes (DeGraaf and Rappole 1995). This information gap is of critical importance as non-breeding season events can strongly affect the survival and reproductive success of migratory passerines (Rappole and McDonald 1994, Rappole et al. 2003, Marra et al. 1998, Sherry and Holmes 1996, Sherry et al. 2005, Norris et al. 2004). Even the extent of the GWWA non-breeding range has not yet been adequately delineated. This deficiency is evidenced by the difference in the range estimate provided by published literature (Ridgely et al. 2007; Figure 1.2a) and the records accumulated by the online, open-access bird observation database, eBird.org (Figure 1.2b). The eBird observations expand the estimated non-breeding range closer to the Pacific slope of Honduras, El Salvador, and Guatemala than previously documented. The northern extension appears to be much broader than that shown in the Ridgely et al. (2007) dataset as well, extending throughout northern Guatemala, Belize and into the Yucatan of Mexico. 


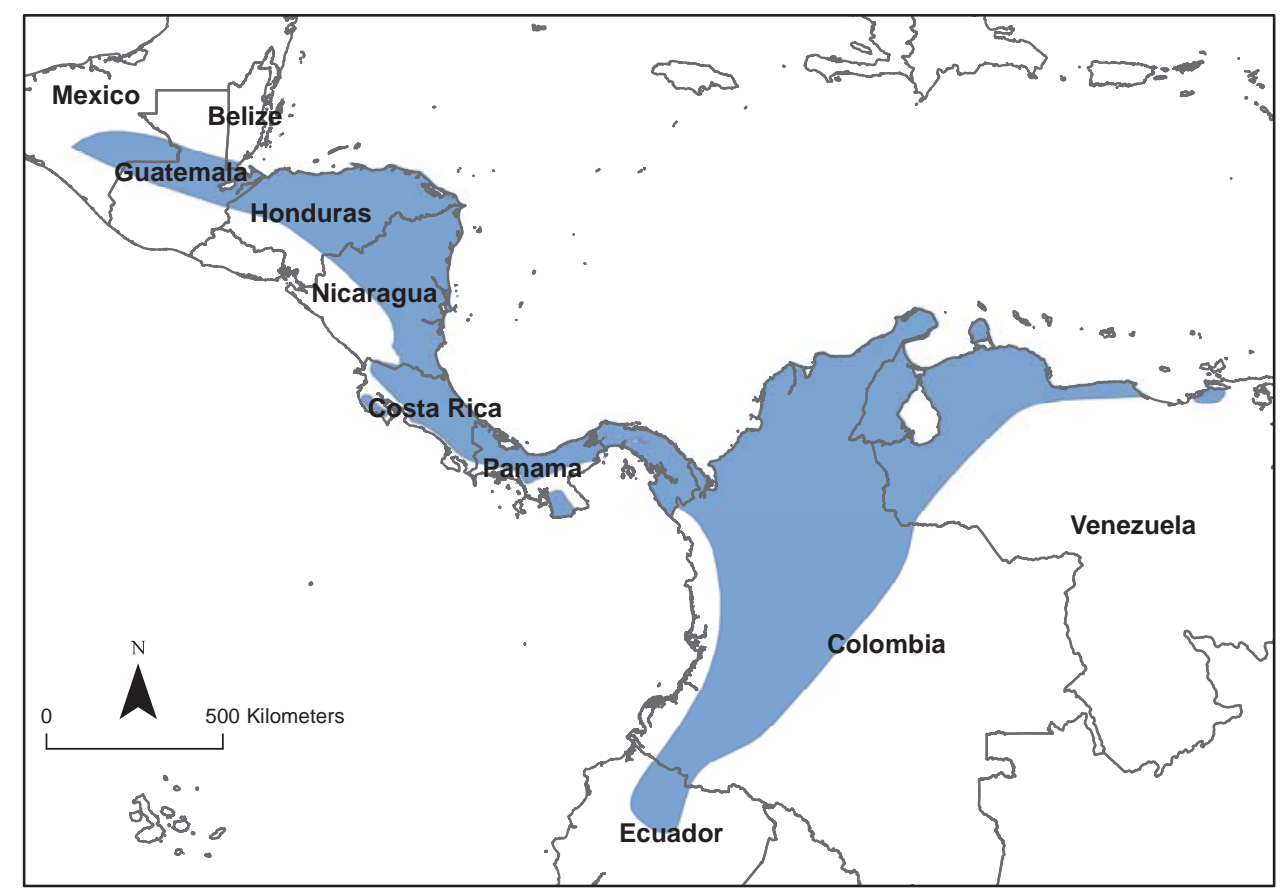

a: GWWA non-breeding distribution range map. Data by NatureServ (Ridgely et al. 2007).

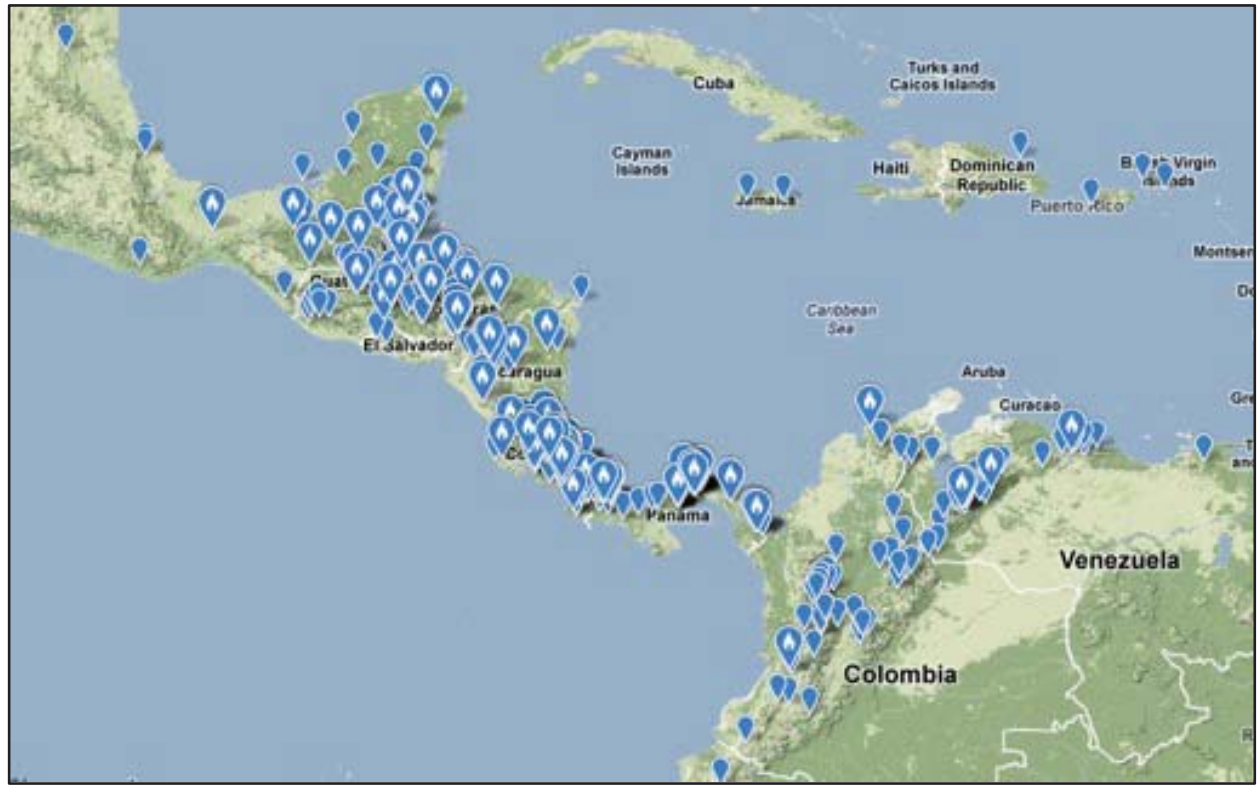

b. Observations of GWWAs from November through February across all years. Larger icons are records from birding hotspots while small icons are individual observations. Occurrence on the Caribbean Islands is rare. Image provided by ebird (ebird.org) and created October 16, 2012.

Figure 1.2: A comparison of (a.) the published non-breeding range map and (b.) birder observations of GWWAs during the non-breeding season. 
In 2009, the project Alianza Alas Doradas (Golden-winged Alliance) commenced, seeking to address the lack of information on GWWA distribution, density, and ecology during the non-breeding season (Will et al. unpublished data). Local collaborators conducted hundreds of point count surveys in Nicaragua, Costa Rica, Panama, and Columbia that specifically targeted GWWAs through playback of recorded GWWA vocalizations. An initial analysis of the data suggests that at a landscape scale, the probability of GWWA presence increases with temperature and precipitation and peaks at middle elevations (Wills et al. unpublished data). These predictions are supported by Chandler and King (2011) who found that GWWAs were absent from tropical dry forest on the Pacific slope of Costa Rica and most common in pre-montane broadleaf forest receiving 2.5 meters of rainfall a year. Landscape scale factors are useful for predicting presence of GWWAs in areas without data, but they most likely allow for the conditions that support directly selected microhabitat characteristics, rather than being directly selected themselves. Specifically, GWWAs display specialized foraging behavior in the non-breeding season; the majority of their feeding actions consist of probing inside dead, hanging leaves and to a lesser extent gleaning and probing live leaves and moss (Chandler 2011, Tramer and Kemp 1980). Accordingly, GWWA presence is correlated with the presence of dead leaves, which appear to be most abundant in broadleaf forests with intermediate levels of disturbance such as riverbanks, landslides, and canopy gaps (Chandler 2011).

Most studies that document the distribution and habitat associations of GWWAs consider only the southern half of the non-breeding range, especially Costa Rica, Panama, and Colombia (Orejula et al 1980, Blake and Loiselle 2001, Powell et al. 1992, Chandler and King 2011, Wills et al unpublished data). Combined, these countries possess markedly different climates and forest systems than the northern half of the non-breeding range. Overall climate becomes drier north of Costa Rica, which suggests precipitation may not play a strong role in habitat selection when considering the entire non-breeding range (Hijmans 2005). Pine forests (Pinus spp.), which comprise 23\% of Honduran land cover, reach their southernmost distribution in northern Nicaragua (Rivera et al. 2011, 
Critchfield and Little 1966). Pine forests are very different in structural composition from humid broadleaf and tropical dry forests, yet previous studies have overlooked the suitability of pine-oak forests as non-breeding habitat for GWWAs. The need for data from the northern portion of the non-breeding range is critical to improve our understanding of the distribution, habitat associations, and threats faced by the GWWA.

Published reports of GWWAs in Honduras are few. In a historic synthesis of published sightings and museum specimens collected in Honduras, Monroe (1968) documented that GWWAs occur infrequently in the primary and secondary broadleaf and pine-oak forests of the Caribbean slope and interior highlands of the country. Monroe (1968) recorded museum specimens from seven locations in the country that were collected at sea level to 1800 meters above sea level. As is true in the southern part of the non-breeding range, the GWWA is not evenly distributed throughout Honduras. Records and personal communication indicate that the bird likely avoids the Pacific lowlands, the pine savannahs (Pinus caribaea) of La Moskitia, and dry thorn forest found in rain-shadow valleys (Monroe 1968, Anderson et al. 2004, R. Gallardo pers. comm.). Unfortunately, these records do not indicate why GWWAs select and avoid certain habitats, which habitats are most suitable, and what factors are threatening GWWA habitat in Honduras.

To address this critical information gap, I designed a study that would assess GWWA distribution and habitat use at multiple scales across the Honduran landscape. I considered both landscape scale variables that indicate presence in the southern portion of the range as well as microhabitat features. 


\section{Methods}

\section{Study Area}

I selected eight study sites in Honduras in areas where GWWAs had been previously observed (personal observation and R. Gallardo pers. comm., Figure 2.1). The sites occurred within three major forest systems and represented a range of land cover classes. Semi-deciduous broadleaf forest was present at Catacamas in a fragmented agricultural matrix. Forest cover is sparse in Catacamas and exists mainly in forested stream corridors and narrow strips along property boundaries between cultivated fields and pastures. La Muralla, Opatoro, and Celaque occur within a conifer-broadleaf mixed forest. Ocote pine (Pinus oocarpa) dominates these landscapes with oak (Quercus spp.) and other broadleaf species are present in lower densities. These three sites occur in mountainous terrain characterized by dry pine savannah on the hilltops and dense, shrubby, broadleaf vegetation filling narrow arroyo valleys. At elevations above 1800 meters, these forests change to montane broadleaf. Forest fragmentation is moderate to low in the coniferbroadleaf sites, though anthropogenic pressure does exist from livestock grazing, rotational pine harvesting, and forest clearing for crop cultivation. Evergreen broadleaf forest occurs in areas of high precipitation throughout Honduras, and is represented at Lancetilla, Yojoa, Parque Nacional Cerro Azul Miambar (PANACAM), and Montaña Santa Barbara. These sites vary greatly in elevation, ranging from the sea level at Lancetilla to 1800 meters at Santa Barbara. Degree of forest fragmentation varies greatly within these sites. Reforestation and regrowth occur within the national park boundary of PANACAM and primary cloud forest still exists at 1800 meters in Santa Barbara. However, forest clearing for coffee production, tree plantations, and small-scale cultivation affect all sites. Additional site information is located in Appendix A. 


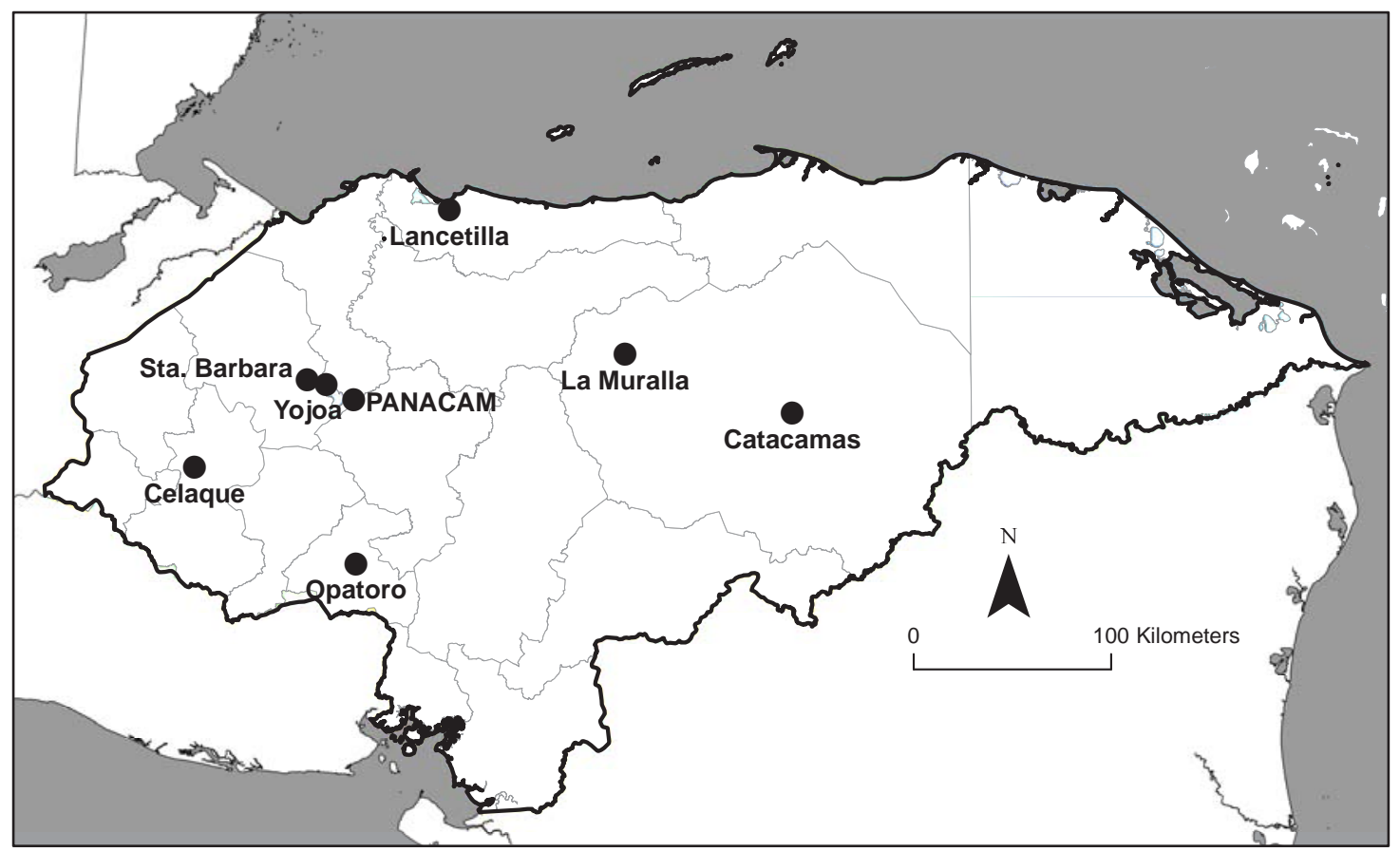

Figure 2.1: Map of Honduras with the locations of the eight study sites. Country data from ESRI ${ }^{\circledR}$ (2011).

\section{Bird Surveys}

At each study site, I established 10 survey points spaced approximately 500 meters apart. I conducted a point-count survey at each point on three separate days with two exceptions. The points in Opatoro were only visited twice, and only nine survey points were established in La Muralla. In total, I conducted 227 point-count surveys at 78 unique points. In Costa Rica, telemetry data indicated that GWWAs establish fixed nonbreeding territories by the beginning of November and remain on fixed territories until the end of March (Chandler 2011). I surveyed all points between November 15, 2011 and March 15,2012, a time period that conservatively estimates the stationary, non-breeding season.

Each point-count survey included a 10-minute observation-only period and 10-minute vocalization playback period. During the playback period, which increases the probability of detection (Kubel and Yahner 2007), I broadcast a recorded GWWA 
vocalization developed by the Cornell Lab of Ornithology from a hand-held mp3 player and speaker. Several different speaker models were used, but all broadcast the GWWA vocalizations at a volume approximate to that of an actual individual and were successful at eliciting a response present GWWAs. The recording consisted of the Type A song ("bee bzz bzz bzz"), the alternate Type B song (a trill), and the chip note (Dunn and Garrett 1997). As both the GWWA and BWWA have a very similar Type B song, which is used in aggressive interspecific interactions (Gill and Murray 1972), I assumed the broadcast vocalization targeted both warblers, albeit unequally in playback time duration. I conducted an extended 25-minute point-count survey on one of the three visits, in which I broadcast an owl-mobbing playback developed by Ken Rosenburg at Cornell Lab of Ornithology for the five minutes following the GWWA survey. The owlmobbing playback features vocalizations of the Ferruginous Pygmy-Owl (Glaucidium brasilianum) and the Eastern Screech-Owl (Megascops asio) along with the mobbing calls of various Neotropical resident and migratory birds. The playback targeted small passerines and hummingbirds, and I recorded all species detected during the extended survey.

In order to identify individual GWWAs, I conducted targeted mist-net captures and banded captured birds with a unique combination of two color bands. I assumed that GWWAs were the same individual if I identified one by color bands or if I detected a bird at the exact same location as a previous detection (i.e. on a fixed territory). All other birds were assumed to be new individuals. I did not actively target BWWAs or BRWAs for capture though I did incidentally capture and band one of each. I assumed that birds located at the same exact same spot on multiple days were the same individual.

\section{Habitat Surveys}

I established a habitat survey plot at the location of each point-count and at locations where I incidentally observed a GWWA or BWWA. At each plot center, I recorded the elevation and geographic coordinates using a handheld geographic positioning system 
(GPS) and the slope and aspect with a compass. The majority of GWWA foraging activity consists of probing and gleaning for insects in vines, hanging dead leaves, and epiphytes (Chandler 2011). I recorded the density of those three microhabitat features in four quadrants within a 50-meter radius of the plot center using a 1-4 index (Table 2.1; Figure 2.2).

Table 2.1: Description of microhabitat indices (Adapted from Chandler 2011)

\begin{tabular}{clll}
\hline Index & Vines & Dead Leaves & Epiphytes \\
\hline 1 & absent & absent & absent \\
2 & some single vines & $1-100$ & $1-20 \%$ coverage of branches \\
3 & many singles \& 1 vine cluster & $100-1000$ & $\begin{array}{l}20-50 \% \text { coverage of branches } \\
\text { many singes \& 2+ vine }\end{array}$ \\
4 & $>1000$ & $\begin{array}{l}>50 \% \text { coverage of branches and } \\
\text { trunk }\end{array}$ \\
\hline
\end{tabular}

Within a 100-meter radius of the plot center, I recorded the percent cover and characteristics of all habitat types present (Figure 2.2). I classified habitat types into the following categories: primary forest, secondary forest, natural disturbance (forest with canopy gaps, landslides, steep river banks), agroforest (shade coffee, orchards, tree plantations), guamil (fallow fields with two to four meters of woody growth), no overstory (pasture and non-woody crops), and wetland. In each habitat type present, I measured percent canopy cover and average canopy height. Canopy cover, as defined by Jennings et al. (1999), was estimated using a flat 2.5 in. ${ }^{2}$ mirror with an angle of observation of less than five degrees. I took five readings spaced 10 meters apart and averaged the values in each habitat type that was present. I estimated canopy height by measuring the height of one tree representative of the apparent canopy height with a clinometer. To consider the effect of fragmentation, I recorded

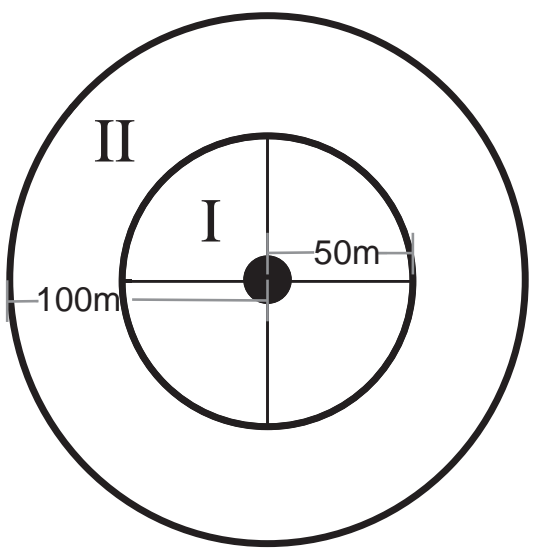

Figure 2.2: Nested structure of habitat surveys. Microhabitat characteristics were recorded in the four "l" quadrants. Habitat type and associated characteristics were recorded in the $100 \mathrm{~m}$ radius "II" circle. 
presence of a edge within the $100 \mathrm{~m}$ plot. Dirt roads, trails and, small streams were not considered edge if they did not disrupt the canopy. Edge was classified according to five classes: no overstory, new stand, natural disturbance feature, water feature, and guamil. The new stand category accounts for edge between a secondary forest and an agroforestry system such as coffee or cacao as well as an edge that occurs naturally between two forest stands (i.e. pine and broadleaf). I also recorded water features within 250 meters of the plot center by measuring distance to the first water source and width of the water. Water features were classified as: wetland, spring, irrigation ditch, stream, river, and pond/lake. This nested sampling approach captures the landscape characteristics of the Golden-winged Warbler territory as well as the presence of microhabitat features that may selected within a territory.

\section{Estimating Climatic Variables}

I examined the effect of temperature and precipitation on GWWA presence as those climatic variables have been used to predict GWWA presence in the non-breeding range (Will et al. unpublished data, Chandler and King 2011). To determine temperature and precipitation values, I plotted the GPS coordinates from my data points on the 30 arcsecond ESRI ${ }^{\circledR}$ climate data grids from the WorldClim dataset (Hijmans et al. 2005). Using ArcMap 10.1 (ESRI 2012), I extracted the monthly mean temperature values and annual precipitation values for all of my data points. I used the mean temperature of the month of November in my analysis, as November temperature was correlated with the means from all months $(R=.96)$ in the non-breeding season and most accurately represents the beginning of the non-breeding season when habitat selection takes place.

\section{Analysis}

To analyze the microhabitat density indices, I added the four quadrants together, creating a summative index of four to sixteen for each feature. Before conducting any statistical analysis, I checked habitat variables for collinearity. Elevation was negatively correlated 
with mean November temperature $\left(p<0.001, R^{2}=0.96\right)$ and the vine index $(p<0.001$, $\left.R^{2}=0.21\right)$, but was positively correlated with slope ( $p<0.001, R^{2}=0.25$ ). Although the $R^{2}$ value shows a weak goodness of fit for the elevation regressions with the vine index and slope, I did not use these variables in any models that also considered elevation. I used a variety of logistic models to test the null hypothesis that GWWAs are detected equally in all plots regardless of habitat differences. For all logistic models, I compare habitat data from the locations where I observed GWWAs ( $\mathrm{n}=61)$ and the locations surveyed multiple times with no GWWA detections ( $\mathrm{n}=65$ ). It is important to note that plots without detection of a GWWA are not necessarily habitat that a GWWA has avoided. Point-count detection is imperfect and seemingly unoccupied plots may still have been used by a GWWA (i.e. false negative observation). Alternatively, suitable habitat may exist in more plots than are used by GWWAs. If survival is lower during the breeding season and migration than during the stationary, non-breeding season, then suitable habitat may be underutilized in Honduras. The simple logistic analysis I conducted does not account for imperfect detection probability or temporal changes in occurrence. However, as I did not collect data over multiple field seasons or test for the probability of detection, logistic regression provides a suitable analysis of the habitat differences between the points with and without GWWA detections. For all logistic models, I reported $p$ values calculated by the Wald test. I used a two-sample T-test to test the difference in habitat variable means between male and female GWWAs or between BWWAs and GWWAs. To test if habitat types or forest systems varied between plots with and without GWWA detections, I used a Fisher's exact test if any category have count values less than five and a Chi-squared test if all categories have count values greater than five. This initial analysis allowed me to reduce the number of variables I considered to be associated with GWWA presence. To then determine the variables which best explain GWWA occurrence, I created a logistic model that included the habitat variables shown to be significant in the initial analysis. I tested its goodness of fit against a backward stepwise selected model by comparing AICc values and by testing a null hypothesis that there is no difference in explanatory power between models with a Chi-squared test. All statistics were analyzed using R version 2.15.1 (2012). 


\section{Results}

I detected 51 individual GWWAs at 58 locations. Of the 51 individuals, 45 were males detected at 49 locations and 12 were females detected at 12 locations. I observed both sexes together simultaneously at three locations. I detected 20 individual BWWAs at 21 points. BWWAs and GWWAs were both detected at eight locations, though not always simultaneously. I observed two BRWA at three locations. The BRWAs were not included in the analysis due to insufficient detections. I surveyed 50 additional points in which I did not detect any Vermivora species. Detection frequency by species and sex based on the three survey periods and incidental observations are shown in Figure 3.1a-c and are significantly different with Fisher's exact test $(p<0.001)$. The distribution of all Vermivora detections is shown by species in Figure 3.2a and by GWWA sex in Figure $3.2 b$.

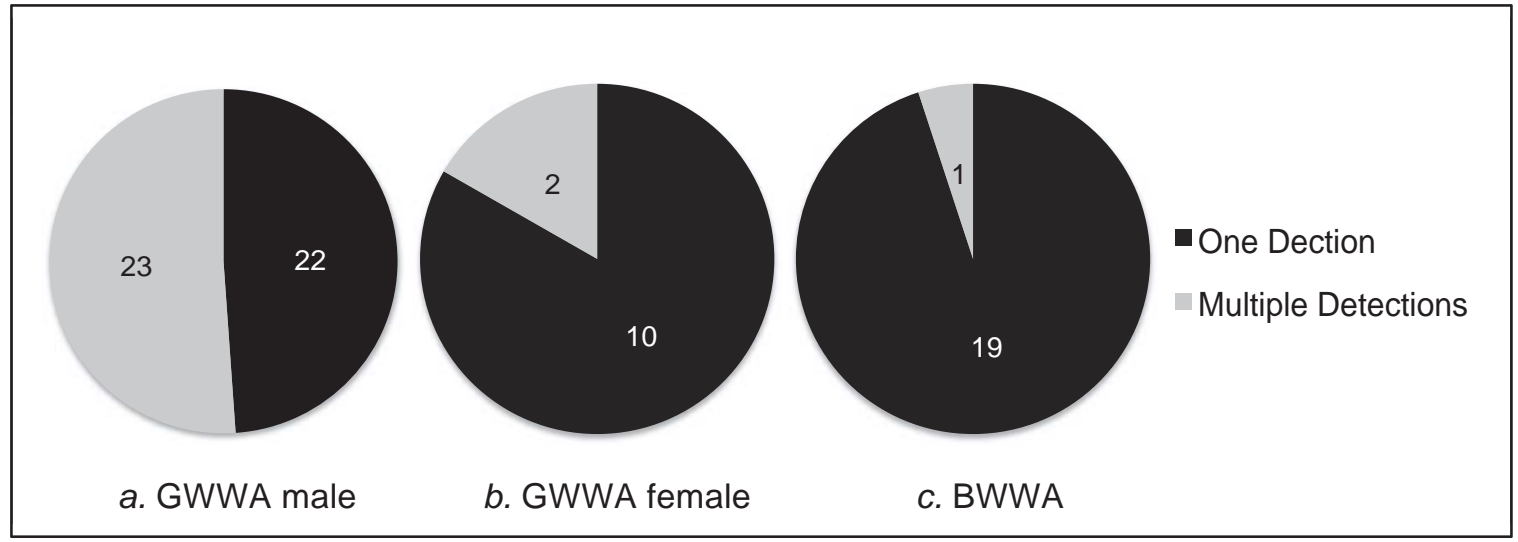

Figure 3.1: Difference in frequency of detection between Vermivora species and sex shown by number of individuals detected just once as compared to multiple times.

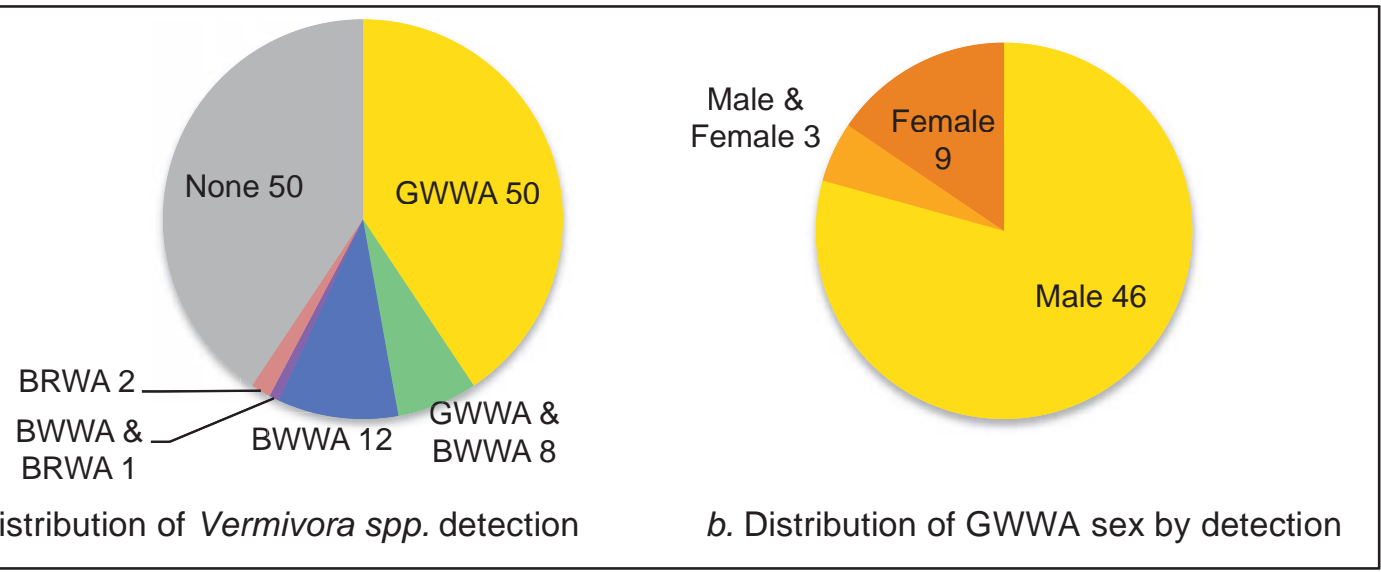

Figure 3.2: Distribution of Vermivora species detections. 


\section{Spatial Segregation by Vermivora Species}

The relationship between BWWAs and GWWAs on the non-breeding grounds is relatively undocumented. While this study did not specifically seek to detect BWWAs, many responded actively to the GWWA and owl-mobbing playback, allowing for comparison between their habitat associations. I observed BWWAs at lower elevations and somewhat shorter forest than GWWAs (Figure 3.3). With respect to these variables, I compared BWWA detections to GWWA detections with a logistic regression. Elevation was significantly lower for BWWA detections $(p<0.01)$, but I failed to detect a significant difference in mean canopy height $(p=0.14)$.

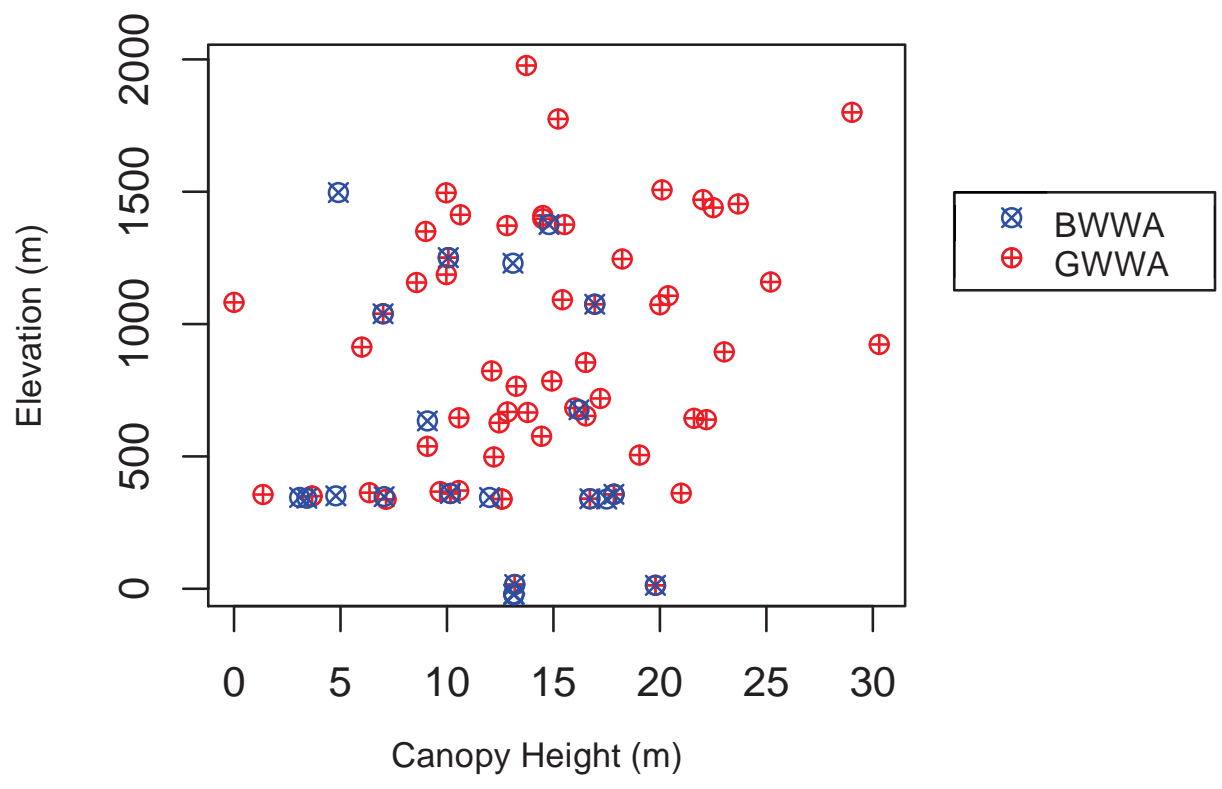

Figure 3.3: Scatterplot of GWWA and BWWA detections with respect to elevation and canopy height.

\section{Spatial Segregation by Sex}

I detected fewer female than male GWWAs (Figure 3.2b). I found females at significantly lower elevation than males (two-sample T-test $p<0.001$; Figure 3.4). I also stopped observing females earlier in the non-breeding season than males. I observed the last female on January 30, 2012, while I continued to detect males until March 14. Elevation and date were strongly correlated in my study $\left(R^{2}=0.69, p<0.001\right)$ as I 
surveyed lower elevation sites early in the season. This complicates the process of determining whether the difference in female and male detections was an effect of elevation, decreased female response to the playback due to date, or a combined effect of both factors. However, an elevation map of Catacamas shows strong elevational segregation by males and females for detections made within a three-week period (Figure $3.5)$.

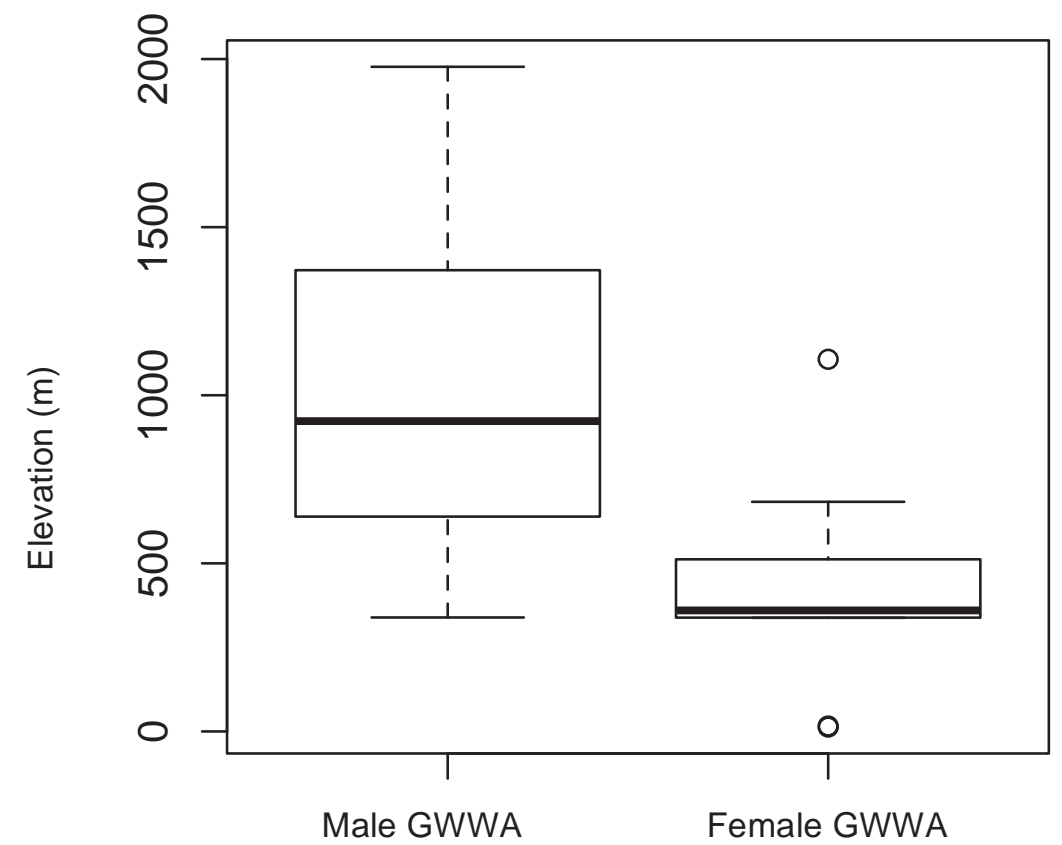

Figure 3.4: Boxplot of the elevation range at which male and female GWWAs were detected.

\section{Forest System and Habitat Type}

I detected GWWAs in all targeted forest systems. For both survey points and incidental observations, semi-deciduous broadleaf forest had the highest rate of GWWA detections (Table 3.1). I tested difference in occurrence across forest systems with a Fisher's exact test, but failed to reject the null hypothesis that occupancy rates do not differ significantly between forests ( $p=0.18$ for survey points, $p=0.13$ for survey and incidental points). 


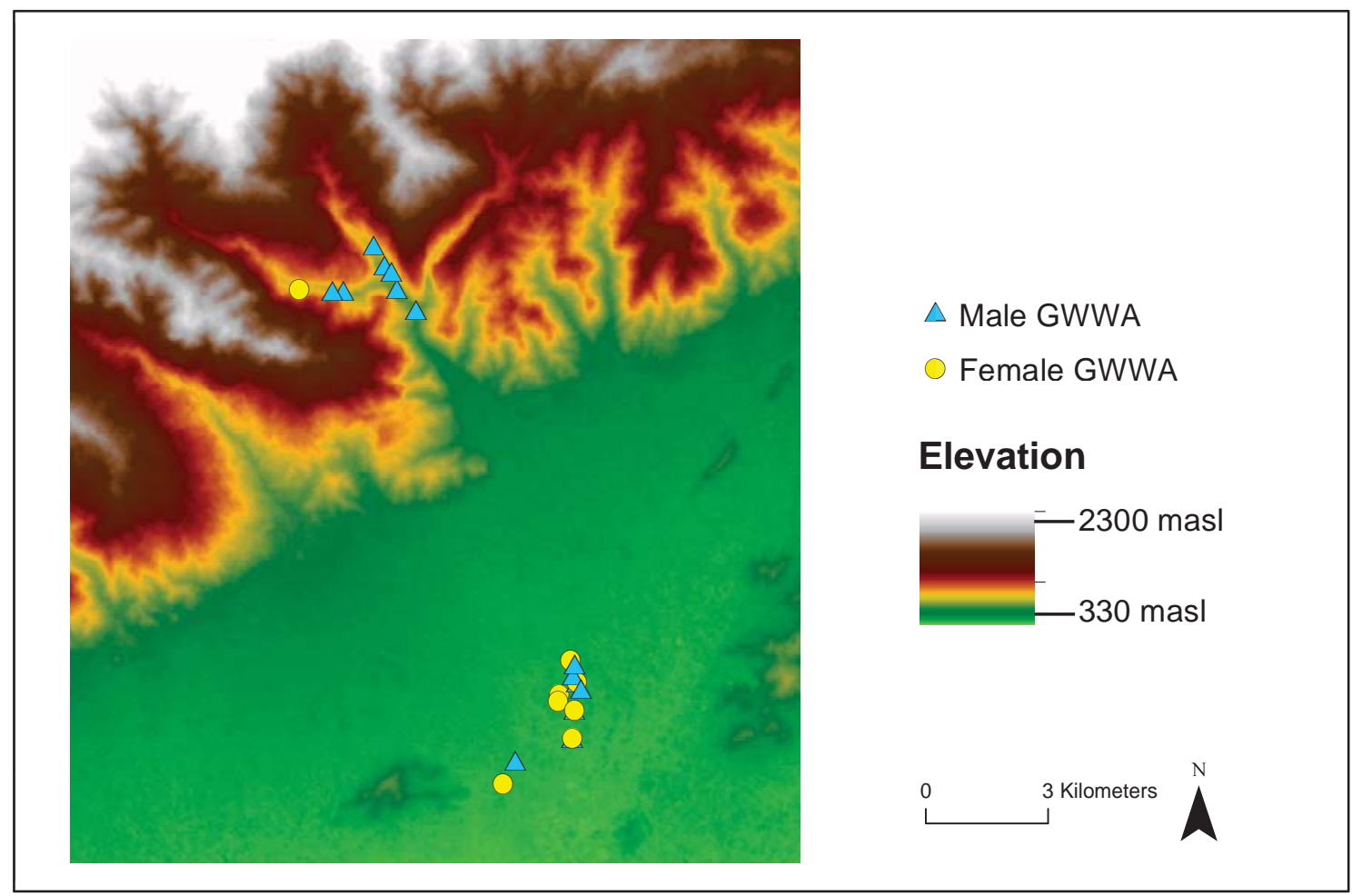

Figure 3.5: Male and female GWWA detections on an elevation map in Catacamas, Olancho. Detections in the green valley occurred in an agricultural matrix with patches of semi-deciduous broadleaf forest. The detections in the mountains occurred in secondary evergreen broadleaf forest. Elevation data from NASA (2011) ASTER Global DEM V2.

Table 3.1: Rates of GWWA occupancy by forest system. Observation points include both survey points and locations of incidental detections.

\begin{tabular}{lccc}
\hline & $\begin{array}{c}\text { Semi-deciduous } \\
\text { Broadleaf }\end{array}$ & $\begin{array}{c}\text { Conifer- } \\
\text { Broadleaf Mix }\end{array}$ & $\begin{array}{c}\text { Evergreen } \\
\text { Broadleaf }\end{array}$ \\
\hline Survey points with GWWA & 5 & 8 & 8 \\
Total survey points & 10 & 29 & 40 \\
Rate of occupancy & 0.50 & 0.28 & 0.20 \\
\hline Observation points with GWWA & 14 & 23 & 24 \\
Total observation points & 19 & 44 & 56 \\
Rate of occupancy & 0.74 & 0.52 & 0.43 \\
\hline
\end{tabular}

Across all habitat types, I detected GWWAs most frequently in secondary forest, which was the dominant habitat in all sites surveyed (Figure 3.6). Although I detected GWWAs with slightly higher frequency in secondary and naturally disturbed forest and slightly 
lower frequency in no overstory systems, there was no significant difference in the habitat type composition of plots with and without GWWA presence $(p>0.95)$.

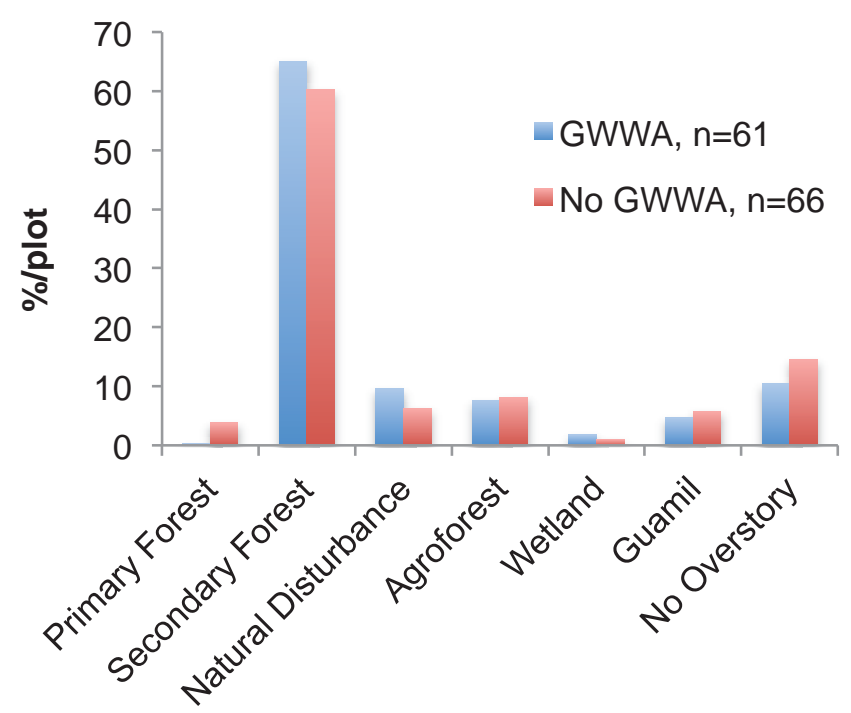

Figure 3.6: Average percent composition of habitat types in a 100-meter radius for plots with and without a GWWA detection.

\section{Habitat Characteristics}

To consider the effect of canopy coverage and canopy height on GWWA presence, I created a forest category by combining the primary, secondary, natural disturbance, agroforest, and guamil habitat types. I observed that GWWAs were common at intermediate forest heights, and a kernel density smoothed histogram shows that GWWA detections peaked at a canopy height of 14.5 meters, which is nearly identical to the no GWWA mean of 14.2 meters (Figure 3.7). However, when considering canopy height as a quadratic variable, the difference between GWWA presence and GWWA absence plots is significant as GWWA probability increases in the taller forests surveyed $(p<0.05$, Table 3.2, Figure 3.7). I did not find a relationship between canopy coverage and GWWA presence $(p=0.93)$. 


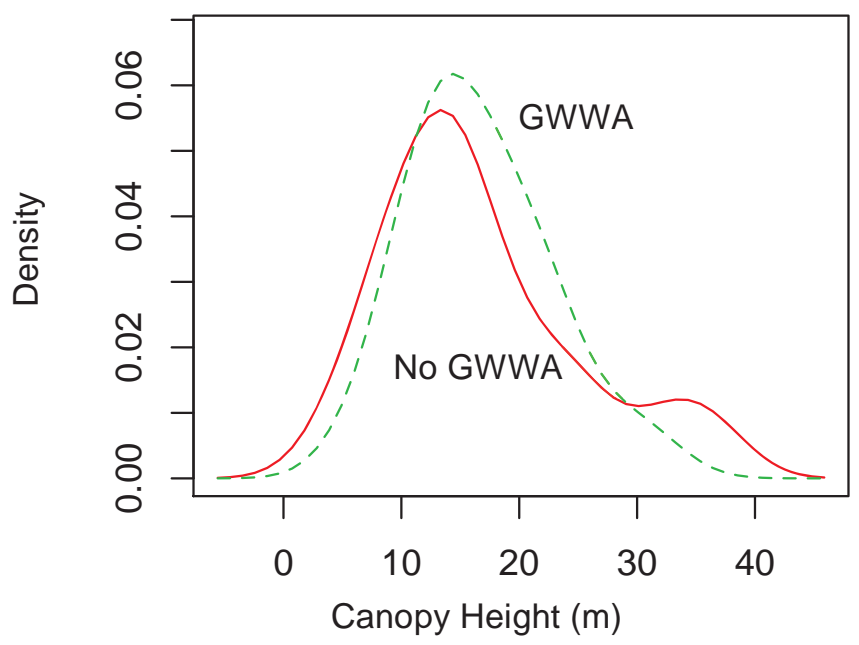

Figure 3.7: Kernel density distribution of GWWA detections across canopy height compared with points without GWWAs.

Table 3.2: Statistics for the logistic regression relating canopy height to GWWA presence

\begin{tabular}{lcc}
\hline \multicolumn{3}{c}{ GWWA presence $\sim$ Canopy Height + Canopy Height ${ }^{2}$} \\
\hline \multirow{3}{*}{$\beta_{0}$} & $\boldsymbol{z}$ & $\boldsymbol{p}$ \\
Canopy Height & -2.5 & $<0.1$ \\
Canopy Height $^{2}$ & 2.7 & $<0.05$ \\
\hline
\end{tabular}

I considered the effect of the three microhabitat variables (vines, dead leaves, and epiphytes) on GWWA occupancy in a logistic model. The dead leaf index was the only significant microhabitat predictor $(p<0.05)$. I also considered the effect of the presence of water features on the landscape within a 50,100, and 250-meter radius of the plot center. Water was only a significant predictor of GWWA presence when considered within the 250 -meter radius $(p<0.05)$.

In the field, I observed GWWAs to be most common at lower middle elevations. The majority of detections occurred between 400 and 1200 meters above sea level and followed a quadratic shaped distributed (Figure 3.8). I considered elevation as a quadratic 
variable due to the shape of the distribution, and elevation ${ }^{2}$ was a significant predictor of GWWA presence (Table 3.3).

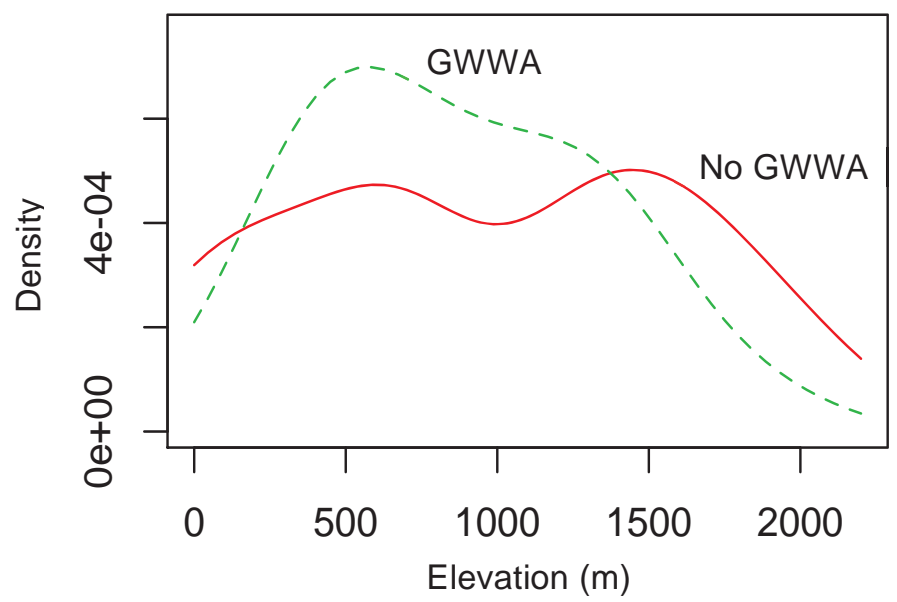

Figure 3.8: Kernel density distribution of GWWA detections across elevation compared with points without GWWAs.

Table 3.3: Results for the logistic regression considering elevation as a quadratic predictor of GWWA presence

\begin{tabular}{lcc}
\hline \multicolumn{3}{c}{ GWWA detection $~$ Elevation + Elevation $^{2}$} \\
\hline & $\boldsymbol{z}$ & $\boldsymbol{p}$ \\
$\beta_{0}$ & -1.8 & $<.05$ \\
Elevation & 2.7 & $<.01$ \\
Elevation $^{2}$ & -3 & $<.01$ \\
\hline
\end{tabular}

\section{Edge}

A significant edge existed in $80 \%$ of points with a GWWA detection and $76 \%$ of points without a detection. Type of edge differed significantly between points with and without a GWWA detection with a Fisher's exact test $(p<0.001$, Figure 3.9). When I considered all edge types together in a logistic model, only the water feature edge significantly predicted GWWA occupancy $(p<0.01)$. 


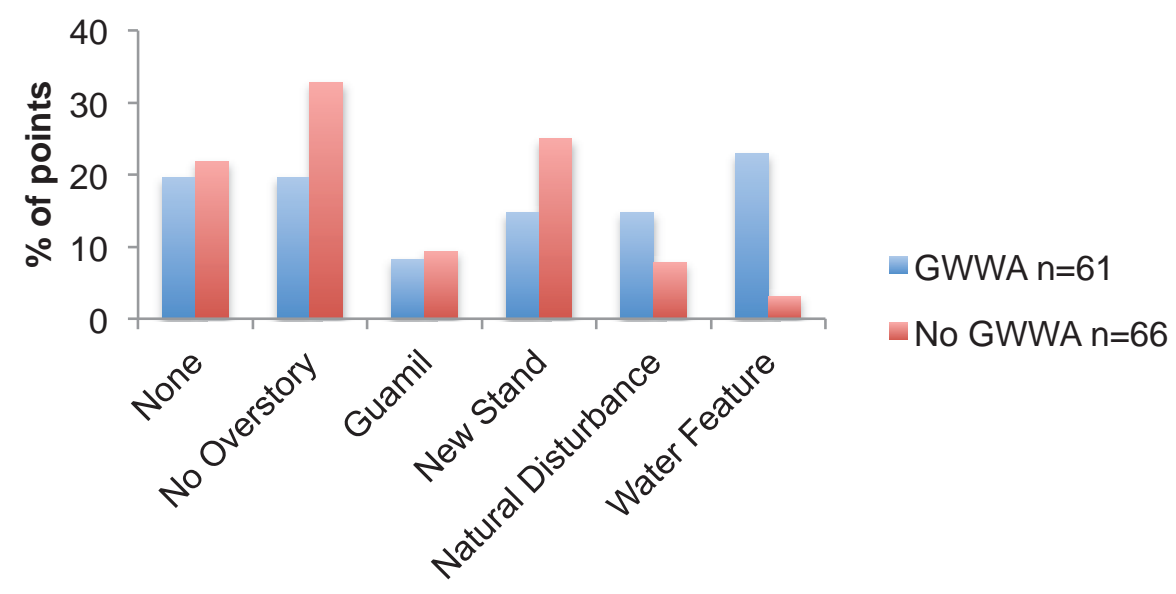

Figure 3.9: Type of edge present for points with and without detection of a GWWA.

\section{Climatic Variables}

With respect to precipitation, the Caribbean slope receives far more annual rainfall than the Pacific slope and interior of Honduras. The annual rainfall map in Figure 3.10 shows the relationship between study sites and precipitation. When considered with a twosample T-test, mean annual precipitation differs significantly between points with and without GWWA detections ( $t=3.1, p<0.01$, Figure 3.11). Caution should be used when interpreting these results however, as there were many GWWA outliers at high rainfall levels. When considering the distribution of the GWWA detections relative to rainfall and elevation, it was apparent that my selection of study sites exclude locations within the intermediate rainfall zone (Figure 3.12). Rainfall also appeared to be correlated with elevation when annual rainfall is less than two meters, as is the case in the majority of the Honduran interior. Elevation does not, however, account for the high annual rainfall that exists on the Caribbean slope and the Lago Yojoa basin. I did not test rainfall with other variables in a logistic model because of the problematic pseudo-collinearity with elevation and the lack of data from the intermediate rainfall zone. 


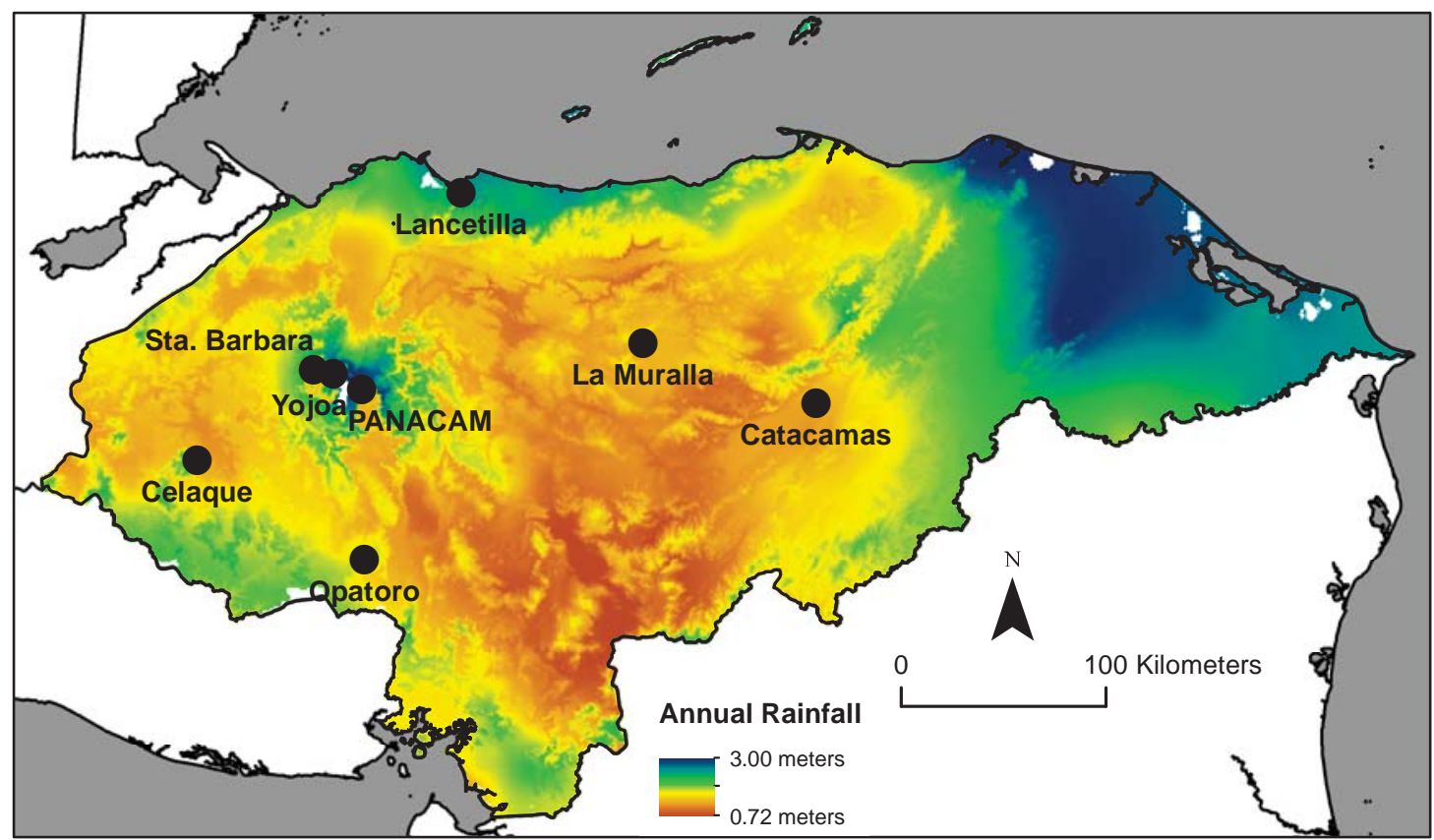

Figure 3.10: Rainfall map of Honduras showing locations of survey areas. Rainfall data from Worldclim.org (Hijmans et al. 2005).

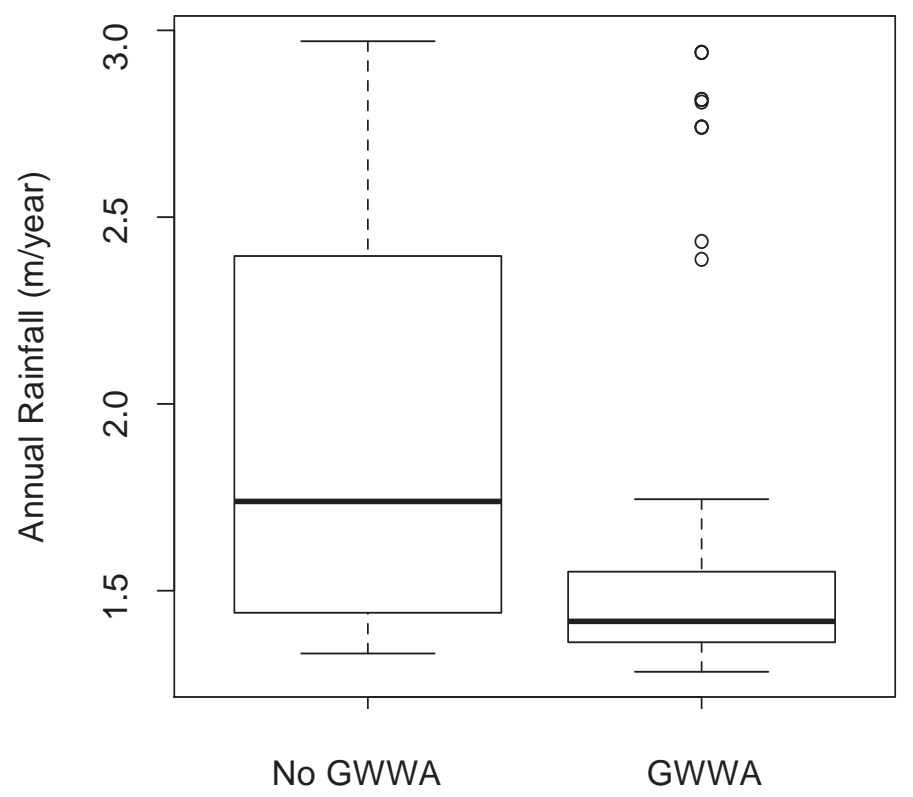

Figure 3.11: Box plot showing the mean rainfall and distribution of points with and without GWWAs. 


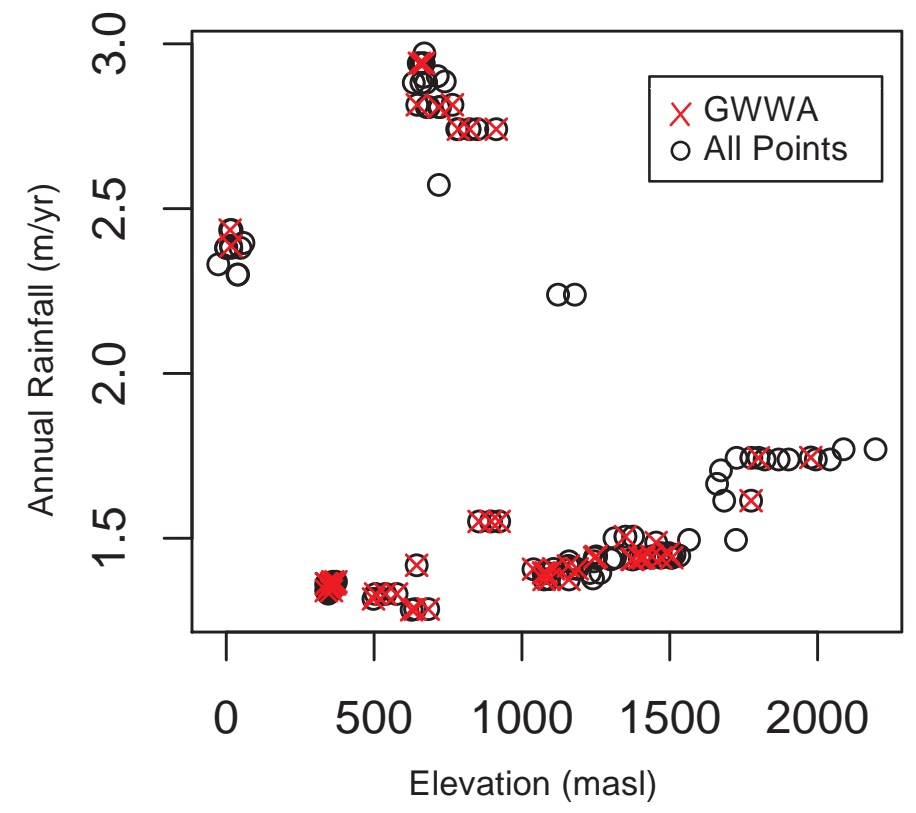

Figure 3.12: Scatterplot of all points across the rainfall and elevation gradient with GWWA detections highlighted red.

\section{Best Fit Model}

I created a logistic model with the habitat variables that I concluded were significant predictors of GWWA presence in Honduras and tested its goodness of fit with backward stepwise selection (Table 3.4). The stepwise selected model better explained GWWA presence than the original model, as evidenced by a lower AICc value. I therefore conclude that all the variables included in the backward selected model are good predictors of GWWA presence on the Honduran landscape, while the eliminated variable of canopy height may not be as important as the other variables.

Table 3.4: Best fit logistic model selected by Backward Stepwise

\begin{tabular}{llr}
\hline Model & Parameters & $\Delta$ AICC \\
$\begin{array}{l}\text { Backward } \\
\text { Selected }\end{array}$ & $\begin{array}{l}\text { GWWA } \sim \text { Elevation + Elevation } \\
\text { within 250m + Dead Leaf Index }\end{array}$ & 0 \\
& GWWA $\sim$ Canopy Height + Canopy Height ${ }^{2}+{\text { Elevation }+ \text { Elevation }^{2}+}$ & \\
Original & Water Feature Edge + Water within 250m + Dead Leaf Index & 4 \\
\hline
\end{tabular}




\section{Discussion}

\section{Spatial Segregation}

The difference in multiple detection rates between GWWAs and BWWAs is not surprising given that I targeted GWWAs with a playback containing three GWWA vocalizations, only one of which is shared with the BWWA. However, of the 20 BWWAs I detected, 18 responded actively to the GWWA playback, evidencing the power of the playback to draw in both species. The other two BWWAs responded to the owl-mobbing playback. I did not detect any BWWAs incidentally without a playback, suggesting BWWAs are extremely difficult to detect in the non-breeding season without a vocalization playback. Overall, BWWAs had significantly fewer multiple detections than did male GWWAs, suggesting that BWWAs ignored the playback more quickly than their GWWA counterparts, many of which responded to the playback on two or three successive days. This also suggests that BWWAs have a lower detection probability than GWWAs when they are only targeted with a GWWA playback. Difference in detection probability may partially account for the difference in the total number of BWWAs detected compared to GWWAs.

The difference in the total number of male and female GWWA detections can be partially explained by the sex based variation in response to the GWWA playback. Of the 12 females observed, $42 \%$ seemed unresponsive to the GWWA playback $(n=5)$, while only $13 \%$ of the males were unresponsive $(n=5)$. Of these ten unresponsive birds, five responded to the owl-mobbing playback but not the GWWA playback, and the other five were observed incidentally without playback use. The owl-mobbing call thus represents an important tool to increase detection of female GWWAs and males that do not exhibit aggressive territoriality on the non-breeding range. Females seem to be less detectable than males overall, though the playback response rates alone may not adequately explain the difference in number of detections. 
Segregation by elevation (Figure 3.4) may partially explain the difference in number of detections, as half the points I surveyed exceeded the observed female elevation range. Other Parulidae species are known to exhibit habitat segregation by sex in their nonbreeding range (Morton et al. 1987, Ornat and Greenbert 1990, Parrish and Sherry 1994). Habitat segregation can affect non-breeding season fitness as well as reproductive success if females occupy lower quality habitat than adult males (Marra and Holberton 1998, Marra et al. 1998). As a consequence of occupying lower quality habitat, female and juvenile male American Redstarts (Steophaga ruticilla) departed for northward migration at later dates, had lower survival during migration, and produced less offspring on the breeding grounds (Marra el al. 1998). However, in the case of the Hooded Warbler (Steophaga citrina), females occupy drier, shrubbier habitats during the non-breeding season by apparent preference rather than intrasexual competition or lack of available high quality habitat (Morton et al. 1987). Further research should focus on female GWWAs to determine if female occupied habitat is of lower quality than male habitat and if females have sex specific habitat requirements. As GWWA males are detected at far higher rates than females in all non-breeding studies, it is possible that conservation efforts may be targeting male GWWA habitat and overlooking female habitat (Chandler 2011, Chavarría and Duriaux 2009). This topic warrants further research.

\section{Forest System and Habitat Type}

Although the rates of occupancy between the three forest systems I surveyed were not significantly different, this study shows that occurrence of GWWAs is not limited to lower and middle elevation tropical wet forest as suggested in recent literature (Chandler and King 2011, Will et al. unpublished data). Studies leading to the assumption that GWWAs only occupy tropical wet forest took place in the southern portion of the nonbreeding range and primarily considered tropical wet and dry forest (Tramer and Kemp 1982, Blake and Loiselle 2000, Orejuela et al. 1980). However, published records documenting GWWAs in other ecosystems exist, including observations, captures, and specimens collected from Central American pine-oak forest (Monroe 1968, Andino and 
Komar 2010, Chavarría and Duriaux 2009). Howell and Webb (1995) stated anecdotally that GWWAs occur in semi-deciduous forest, though I am unaware of a published observation or specimen of a GWWA from that habitat prior to this study. In Nicaragua, GWWAs were detected in pine-oak forest at 10-30\% of point count sites using the same point count protocol I followed (Chavarría and Duriaux 2009). However, the Nicaraguan study suggested that GWWA occur in lower densities in pine-oak forest than humid broadleaf due to lower relative humidity.

While deforestation has occurred in Honduras, pine dominated forest still covers $23 \%$ of the Honduran landscape and humid broadleaf covers 35\% (Rivera et al. 2011). Semideciduous broadleaf is rare enough that it was not considered in this recent MODIS supervised land classification (Rivera et al 2011). The Catacamas Valley was simply classified as "Farm/Pasture" While the Catacamas area is dominated by cultivated land, I observed 14 GWWAs in small patches of remnant forest ( $<20 \mathrm{ha})$ and in narrow gallery forest ( $\sim 50 \mathrm{~m}$ wide) preserved along stream corridors. None of the remnant forest can be considered primary due to tree removal, extensive edge, and heavy cattle grazing, yet it still provides habitat to GWWAs. Most importantly, it is the only site where I detected male and female GWWAs in equal numbers.

\section{Habitat Characteristics}

Many of the habitat characteristics significantly associated with GWWA presence in my study agree with habitat studies from other parts of the non-breeding range (Chandler and King 2011, Chavarría and Duriaux 2009). The relationship between GWWA occurrence and canopy height is similar to that documented by Chandler and King (2011) in Costa Rica, which indicated that GWWAs occurred in greatest densities in forests of medium height. The relationship between GWWA occurrence and elevation, which was supported in my best-fit model, was not a strong variable in Costa Rica, where annual precipitation drove habitat selection more than elevation In contrast, annual precipitation data in this study suggests that GWWAs are found in greater densities in low rainfall 
sites. This contradicts results from Costa Rica, where Chandler (2011) found that GWWA presence peaked at $2.5 \mathrm{~m}$ of annual rainfall while birds were absent from areas with $1.5 \mathrm{~m}$ of rainfall or less. While I did observe GWWAs in areas with rainfall as high as three meters per year, mean annual rainfall for all GWWA points was 1.65 meters with 43 GWWA detections occurring in areas with $1.5 \mathrm{~m}$ or less of annual rainfall. Rainfall may be a good predictor of GWWA density at the scale of one mountain range, but these results indicate that the relationship between GWWAs and rainfall is not consistent across the non-breeding range.

This study identified dead leaves but not vines as an important microhabitat feature associated with GWWA occurrence. The support for dead leaves and not vines in the model may be a consequence of sampling in pine-oak forest. Vine clusters catch and suspend dead leaves dropping from the canopy in humid broadleaf forests and have been significantly associated with GWWA presence, but I observed vines to be largely absent from the pine-oak forest (Gradwohl and Greenberg 1982, Chandler and King 2011). The understory oak trees of the pine-oak system often have single dead leaves scattered throughout the crown or a cluster of dead leaves at the site of a dying branch. Humid valleys or "arroyos" also exist throughout pine-oak forest and the dense thickets and brambles of the steep drainages may also serve to suspend leaf litter. My results suggest that the dead leaves, which may be in present in the crown of a tree, suspended in vine clusters in humid broadleaf, or suspended in the drainage thickets of the pine-oak system are the most important microhabitat feature associated with GWWA occurrence.

Presence of a water feature within 250 meters of a plot center strongly indicated the presence of GWWAs. The scale at which water features were significant is the average size of a GWWA non-breeding range territory (Chandler 2011). Densities of other Neotropical warblers increased relative to the availability of arthropods on the nonbreeding range (Johnson and Sherry 2001), and the humid microclimate created by a water feature may support a higher arthropod density relative to the surrounding landscape (Cloudsley-Thompson 1962). 
I found that GWWAs were negatively correlated with anthropogenic forest disturbance and positively correlated with natural disturbance and water features. While anthropogenic disturbance tends to create a desiccating edge, natural and water disturbance features are characterized by dense woody vegetation surrounded by a closed forest canopy, high density of hanging vines, and high density of dead leaves. Natural disturbance features therefore created conditions more suitable to dead leaf foraging. While GWWAs occurred in small forest patches in the Catacamas Valley, it is possible that these patches do not provide the high quality habitat needed to ensure successful migration and reproduction, due to presence of desiccating edges. Investigating relationships between fragmentation, forest patch size, and habitat quality may provide important insight into the prolonged population decline of the GWWA. 


\section{Conclusion}

Honduras has experienced rapid deforestation and forest fragmentation since the 1950s as a result of logging, farming, coffee production, and cattle ranching (Ludeke 1990, Southworth et al. 2004). Although the Honduran national park system has succeeded in preserving some large tracts of forest, land outside of parks has consistently declined in forest cover (Southworth et al. 2004). Mean elevation for GWWA detection in Honduras (864 $\mathrm{m}$ ) is too low to be protected by the national park system, which was designed to preserve cloud forests above $1800 \mathrm{~m}$ for their function as recharge zones in watersheds. Private reserves, integrated coffee production, and managed forests have potential to maintain suitable habitat for this species. Some large landowners in Olancho protect lowland forest through personal initiative (Bonta 2003). The pine-oak forest I surveyed in La Muralla is currently managed under the direction of a village with 40 inhabitants. Their efforts have preserved much of the pine-oak forest, which is now managed on a sustainable harvest rotation. Conservation efforts should focus on groups such as these, which have the potential to continue to protect area outside of the national park system. Focusing conservation efforts on the protection of existing riparian forest can also help to preserve GWWA habitat.

By providing the first overview of GWWA distribution and habitat associations in Honduras, this study was able to demonstrate GWWA use of habitats previously thought to be suboptimal or unoccupied. The identification of these new habitat associations raises questions worthy of future research. Persistence of a species depends on the survival and reproductive success of its females. Understanding the specific threats to the habitat selected by females is key to GWWA conservation efforts. Also, simple GWWA occurrence across a wide range of forest and habitat types in Honduras does not mean that these areas provide equal resources to maintain fitness or insure the survival of nonbreeding birds. Investigating habitat specific changes in GWWA body condition and stress levels throughout the non-breeding season will help conservationists identify the best quality habitats and areas in which to focus conservation efforts. 


\section{Bibliography}

76 FR 31920. Federal Register Volume 76: 31920. June 2, 2011. [Online]. Available at http://www.gpo.gov/fdsys/pkg/FR-2011-06-02/pdf/2011-13731.pdf

Anderson, D. L., D. A. Wiedenfeld, M. J. Bechard, and S. J. Novak. 2004. Avian

diversity in the Moskitia region of Honduras. Ornitologia Neotropical 15: 447-482.

Andino, L. and O. Komar. 2010. Sexto Informe Annual, Proyecto de Monitoreo Permanente de Aves Terrestres, El Salvador. SalvaNATURA, El Salvador. [Online]. Available at www.salvantaura.org.

Blake, J. G. and B. A. Loiselle. 2001. Bird assemblages in second-growth and old-growth forests, Costa Rica: Perspectives from Mist Nest and Point Counts. Auk 118: 304-326.

Bonta, Mark. 2003. Seven Names for the Bellbird: Conservation Geography in Honduras. Texas A\&M University Press, College Station, TX.

Buehler, D. A., A. M. Roth, R. Vallender, T. C. Will, J. L. Confer, R. A. Canterbury, S. B. Swarthout, K. V. Rosenberg, and L. P. Bulluck. 2007. Status and conservation priorities of GWWA (Vermivora chrysoptera) in North America. The Auk 124: 14391445.

Chandler, R. B. and D. I. King. 2011. Habitat quality and habitat selection of GWWAs in Costa Rica: an application of hierarchical models for open populations. Journal of Applied Ecology 48: 1038-1047.

Chandler, R. G. 2011. Avian Ecology and Conservation in Tropical Agricultural Landscapes with Emphasis on Vermivora chrysoptera. Open Access Dissertations. Paper 333. Available at http://scholarworks.umass.edu/open_access_dissertations/333.

Chavarría, L. and G. Duriaux. 2009. Informe preliminar del primer censo de Vermivora chrysoptera: realizado en Marzo 2009 en la zona norcentral de Nicaragua. [Online]. Available at: http://www.bio-nica.info/Biblioteca/Chavarria2009FinalGWWA.pdf

Cloudsley-Thompson, J. L. 1962. Microclimates and the distribution of terrestrial arthropods. Annual Review of Entomology: 199-222.

Confer, J. L., J. L. Larkin, and P. E. Allen. 2003. Effects of vegetation, interspecific competition, and brood parasitism on GWWA (Vermivora chrysoptera) netting success. Auk 120:138-144.

Critchfield W. B. and E. L. Little. 1966. Geographic Distribution of the Pines of the World. U.S. Department of Agriculture Forest Service, Washington, D.C. 
DeGraaf, R. M. and J. H. Rappole. 1995. Neotropical Migratory Birds. Cornell University Press, Ithaca, NY.

Dunn, J. L. and K. L. Garrett. 1997. A Field Guide to the Warblers of North America. Houghton Mifflin Harcourt, New York.

eBird 2012. eBird: An online database of bird distribution and abundance [web application]. eBird, Ithaca, New York. Available at: http://www.ebird.org.

ESRI 2012. ArcMap: Release 10.1. Redlands, CA: Environmental Systems Research Institute.

ESRI and DeLorme, 2011. World Boundaries and Places Reference Layer for ArcGIS 10.1 .

Gill, F. B. 1980. Historical aspects of hybridization between Blue-winged and GWWAs. Auk 97:1-18.

Gill, F. B. and B. G. Murray. 1972. Song variation in sympatric Blue-winged and GWWAs. The Auk 89: 625-643.

Gradwohl, J. and R. Greenberg. 1982. The effect of a single species of avian predator on the arthropods of aerial leaf litter. Ecology 63:581-583.

Hijmans, R. J., S. E. Cameron, J. L. Parra, P. G. Jones, and A. Jarvis. 2005. Very high resolution interpolated climate surfaces for global land areas. International Journal of Climatology 25: 1965-1978. http://www.worldclim.org/

Howell, S. N. G. and S. W. Web. 1995. A Guide to the Birds of Mexico and Northern Central America. Oxford University Press, New York.

Hunter W. C., D. A. Buehler, R. A. Canterbury, J. L. Confer, and P. B. 2001. Wildlife Society Bulletin 29:440-455.

Jennings S. B., N. D. Brown, and D. Sheil. 1999. Assessing forest canopies and understory illumination: canopy closure, canopy cover and other measures. Forestry 72(1): 59-73.

Johnson, M. D. and T. W. Sherry. 2001. Effects of food availability on the distribution of migratory warblers among habitats in Jamaica. Journal of Animal Ecology 2001: 546560.

Kubel, J.E. and R. H. Yahner. 2007. Detection probability of Golden-winged Warbler during point counts with and without playback recordings. Journal of Field Ornithology 78:195-205. 
Ludeke, A. K. 1990. An analysis of anthropogenic deforestation using logistic regression and GIS. Journal of Environmental Management 31: 247-259.

Mara, P. P., K. A. Hobson, R. T. Holmes. 1998. Linking winger and summer events in a migratory bird by using stable-carbon isotopes. Science 292: 1884-1886.

Marra, P. P. and R. L. Holberton. 1998. Corticosterone levels as indicators of habitat quality: the effects of habitat segregation in a migratory bird during the non-breeding season. Oecologia 116:284-292.

Marra, P. P., K. A. Hobson, R. T. Holmes. 1998. Linking winter and summer events in a migratory bird by using stable-carbon isotopes. Science 282: 1884-1886.

Monroe, B. J. 1968. A Distributional Survey of the Birds of Honduras. Ornithological Monographs, No. 7, Lawrence, KS.

Morton, E. S., J. F. Lynch, K. Young, and P. Mehlhop. 1987. Do male Hooded Warblers exclude females from nonbreeding territories in tropical forest? The Auk 104:133-135.

NASA Land Processes Distributed Active Archive Center. 2011 ASTER GDEM V2. USGS/Earth Resources Observation and Science Center, Sioux Falls, South Dakota.

Norris, D. R., P. P. Mara, T. K. Kyser, T. W. Sherry, and L. M. Ratcliffe. 2004. Tropical winter habitat limits reproductive success on the temperate breeding grounds in a migratory bird. Proceedings of the Royal Society Biology 271:59-64.

Orejula, J. E., R. J. Raitt, and H. Halvares. 1980. Differential use by North American migrants of three types of Colombian forests: 253-264 in A.K. Keast and E. S. Morton eds. Migrant birds in the Neotropics: Ecology, Behavior, Distribution, and Conservation. Smithsonian Institution Press, Washington D.C.

Ornat, A. L. and R. Greenberg. 1990. Sexual segregation by habitat in migratory warblers in Quintana Roo, Mexico. The Auk 107:539-543.

Parrish, J. D. and T. W. Sherry. 1994. Sexual habitat segregation by American Restarts wintering in Jamaica: importance of resource seasonality. The Auk 111:38-49.

Powell, G. V. N., J. H. Rappole, and S. A. Sader. 1992. Neotropical migrant land-bird use of the lowland Atlantic habitat in Costa Rica: a test of remote sensing for identification of habitat in J. M. Hagan and D. W. Johnson, eds. Ecology and Conservation of Neotropical Migrant Landbirds, Smithosian Insitution Press, Washington D.C. 
R Core Team. 2012. R: A language and environment for statistical computing. R Foundation for Statistical Computing, Vienna, Austria. ISBN 3-900051-07-0, URL http://www.R-project.org/.

Rappole, J. H. and M. V. McDonald. Cause and effect in population declines of migratory birds. The Auk 111(3): 652-660

Rappole, J. H., D. I. King, and J. Diez. 2003. Winter vs. breeding habitat limitation for an endangered avian migrant. Ecological Applications 13: 735-742.

Ridgely, R. S., T. F. Allnutt, T. Brooks, D. K. McNicol, D. W. Mehlman, B. E. Young, and J. R. Zook. 2007. Digital Distribution Maps of the Birds of the Western Hemisphere, version 3.0. NatureServe, Arlington, Virginia, USA.

Rivera, S., J. L. Lowry, A. J. Hernández, R. D. Ramsey, R. Lezama, and M. Velázquez. 2011. A MODIS generated land cover mapping of Honduras: a base-line layout to create a national monitoring center. Revista de Teledetección 35: 94-108.

Roth, A. M., R. W. Rohrbaugh, K. Aldinger, M. H. Bakermans, S. Barker Swarthout, D. A. Buehler, J. L. Confer, D. Crawford, C. Friis, R. M. Fowlds, J. L. Larkin, J. Loegering, J. D. Lowe, M. Piorkowski, K. V. Rosenberg, C. Smalling, T. M. Terhune, R. Vallender, T. Will, and P. B. Wood. 2012. GWWA breeding season conservation plan. In A. M. Roth, R. W. Rohrbaugh, T. Will, and D. A. Buehler, eds. GWWA Status Review and Conservation Plan.

Roth, A.M., R.W. Rohrbaugh, T. Will, and D.A. Buehler, editors. 2012a. GWWA Status Review and Conservation Plan. [Online]. Available at www.gwwa.org/

Sauer, J. R., J. E. Hines, J. E. Fallon, K. L. Pardieck, D. J. Ziolkowski, Jr., and W. A. Link. 2011. The North American Breeding Bird Survey, Results and Analysis 1966 2010. Version 12.07.2011. USGS Patuxent Wildlife Research Center, Laurel, MD. [Online]. Available at: http://www.mbr-pwrc.usgs.gov/

Sherry T. W., M. D. Johnson, and A. M. Strong. 2005. Does winter food limit populations of migratory birds? In R. Greenberg and P. P. Marra, eds. Birds of Two Worlds: The Ecology and Evolution of Migration. John Hopkins University Press, Baltimore.

Sherry, T. W. and R. T. Holmes. 1996. Winter habitat quality, population limitation, and conservation of Neotropical-Nearctic migrant birds. Ecology 77: 36-48.

Sibley, D. 2003. The Sibley field guide to birds of eastern North America. Alfred A. Knopf, New York. 
Southworth, J., H. Nagendra, L. A. Carlson, and C. Tucker. Assessing the impact of Celaque National Park on forest fragmentation in western Honduras. Applied Geography 24: 303-322.

Tramer, E. J. and T. R. Kemp. 1980. Foraging ecology of migrant and resident warblers and vireos in the highlands of Costa Rica: 285-297 in A. K. Keast and E. S. Morton eds. Migrant Birds in the Neotropics: Ecology, Behavior, Distribution, and Conservation. Smithsonian Institution Press, Washington D.C.

Will, T. et al., unpublished data. Chapter 1 (In Preparation) In A. M. Roth, R. W. Rohrbaugh, T. Will, and D. A. Buehler, eds. GWWA Status Review and Conservation Plan. [Online]. Available at www.gwwa.org. 


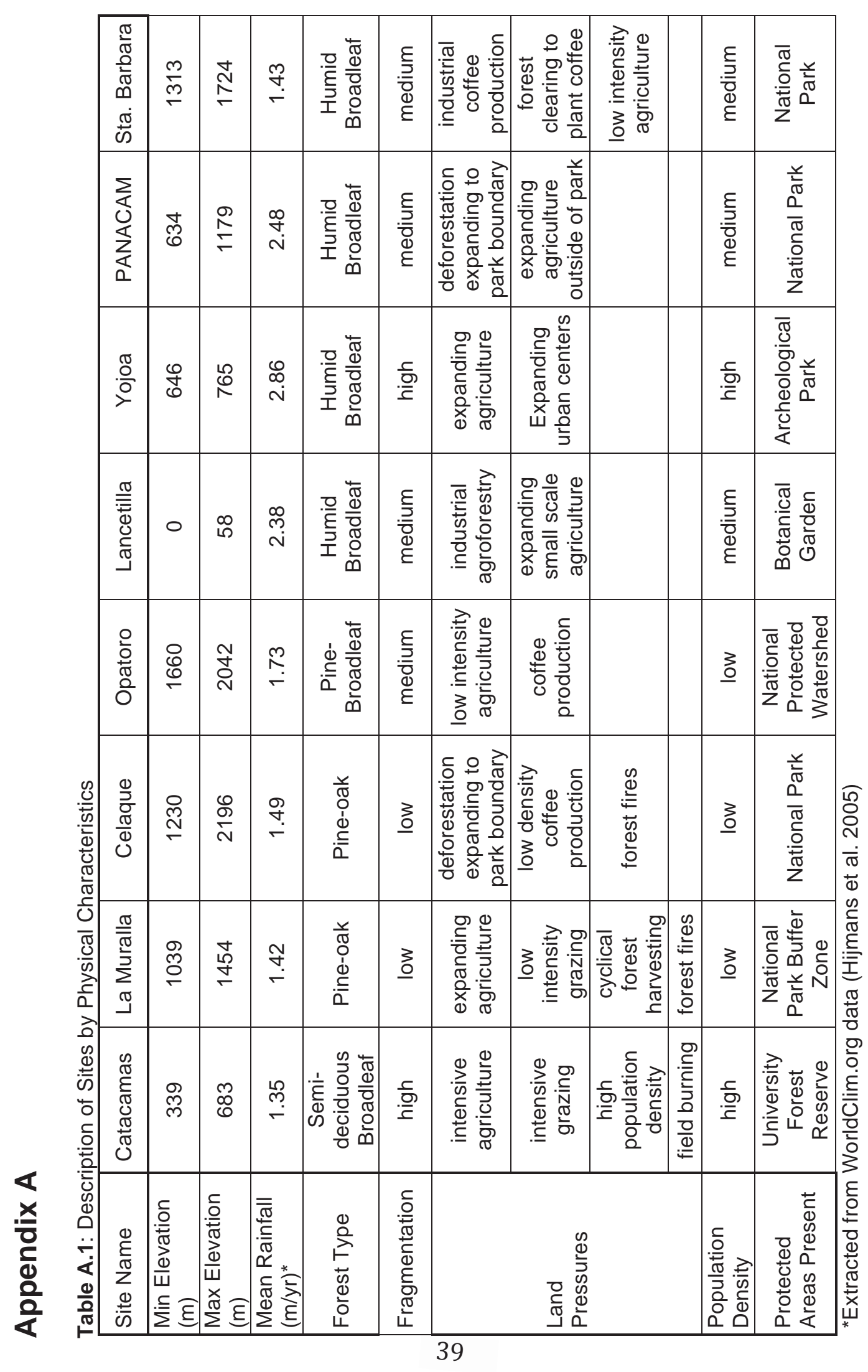




\section{Appendix B}

Table B.1: Percent composition data for plots with a Vermivora detection

\begin{tabular}{|c|c|c|c|c|}
\hline & $\begin{array}{c}\text { GWWA } \\
n=61\end{array}$ & $\begin{array}{c}\text { BWWA } \\
n=21\end{array}$ & $\begin{array}{l}\text { GWWA female } \\
\qquad n=12\end{array}$ & $\begin{array}{c}\text { GWWA male } \\
n=49\end{array}$ \\
\hline \multicolumn{5}{|l|}{ Forest System ${ }^{\star}$} \\
\hline Semi-deciduous Broadleaf & 23 & 38 & 58 & 14 \\
\hline Conifer-broadleaf & 38 & 19 & 8 & 45 \\
\hline Evergreen Broadleaf & 40 & 43 & 33 & 41 \\
\hline \multicolumn{5}{|l|}{$\mathrm{Edge}^{*}$} \\
\hline No edge & 20 & 14 & 8 & 22 \\
\hline Pasture Edge & 20 & 38 & 42 & 14 \\
\hline Agroforest Edge & 5 & 10 & 17 & 2 \\
\hline Forest Edge & 10 & 14 & 0 & 12 \\
\hline Natural Disturbance Edge & 15 & 10 & 0 & 18 \\
\hline Water Feature Edge & 23 & 5 & 25 & 22 \\
\hline Guamil Edge & 8 & 10 & 8 & 8 \\
\hline \multicolumn{5}{|c|}{ Habitat type (100 m radius) ${ }^{*}$} \\
\hline Primary Forest & 0.3 & 0 & 0 & 0.4 \\
\hline Secondary Forest & 65 & 66 & 59.2 & 67.5 \\
\hline Natural Disturbance & 9.6 & 8.1 & 5.8 & 10.5 \\
\hline No Overstory & 10.4 & 17.9 & 19.2 & 8.3 \\
\hline Agroforest & 7.6 & 3.8 & 4.2 & 8.5 \\
\hline Wetland & 1.8 & 2.3 & 2.5 & 1.6 \\
\hline Guamil & 4.7 & 1.9 & 6.7 & 4.2 \\
\hline \multicolumn{5}{|l|}{ Presence of water feature } \\
\hline Water within $250 \mathrm{~m}$ & 82 & 81 & 92 & 80 \\
\hline Water within $50 \mathrm{~m}$ & 57 & 67 & 58 & 57 \\
\hline
\end{tabular}

*Values reported are percentages. Columns may not equal 100 due to rounding. 


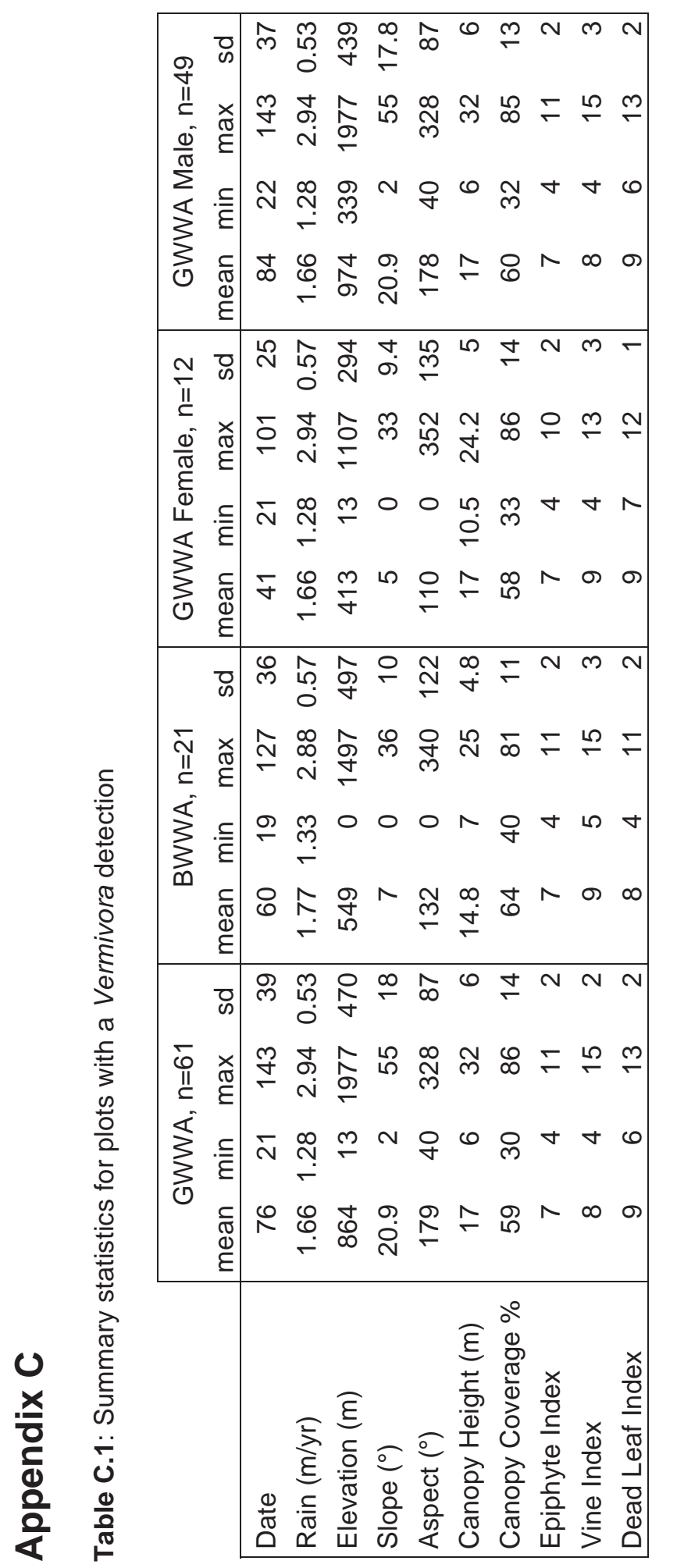

